\title{
Observed temporal evolution of global mean age of stratospheric air for the 2002 to 2010 period
}

\author{
G. P. Stiller ${ }^{1}$, T. von Clarmann ${ }^{1}$, F. Haenel ${ }^{1}$, B. Funke ${ }^{2}$, N. Glatthor ${ }^{1}$, U. Grabowski ${ }^{1}$, S. Kellmann ${ }^{1}$, M. Kiefer ${ }^{1}$, \\ A. Linden ${ }^{1}$, S. Lossow ${ }^{1}$, and M. López-Puertas ${ }^{2}$ \\ ${ }^{1}$ Karlsruhe Institute of Technology, Institute for Meteorology and Climate Research, Karlsruhe, Germany \\ ${ }^{2}$ Instituto de Astrofísica des Andalucía, CSIC, Granada, Spain \\ Correspondence to: G. P. Stiller (gabriele.stiller@kit.edu)
}

Received: 28 July 2011 - Published in Atmos. Chem. Phys. Discuss.: 18 October 2011

Revised: 28 February 2012 - Accepted: 21 March 2012 - Published: 5 April 2012

\begin{abstract}
An extensive observational data set, consisting of more than $10^{6} \mathrm{SF}_{6}$ vertical profiles from MIPAS measurements distributed over the whole globe has been condensed into monthly zonal means of mean age of air for the period September 2002 to January 2010 , binned at $10^{\circ}$ latitude and $1-2 \mathrm{~km}$ altitude. The data were analysed with respect to their temporal variation by fitting a regression model consisting of a constant and a linear increase term, 2 proxies for the QBO variation, sinusoidal terms for the seasonal and semi-annual variation and overtones for the correction of the shapes to the observed data set. The impact of subsidence of mesospheric $\mathrm{SF}_{6}$-depleted air and in-mixing into non-polar latitudes on mid-latitudinal absolute age of air and its linear increase was assessed and found to be small.

The linear increase of mean age of stratospheric air was found to be positive and partly larger than the trend derived by Engel et al. (2009) for most of the Northern mid-latitudes, the middle stratosphere in the tropics, and parts of the Southern mid-latitudes, as well as for the Southern polar upper stratosphere. Multi-year decrease of age of air was found for the lowermost and the upper stratospheric tropics, for parts of Southern mid-latitudes, and for the Northern polar regions. Analysis of the amplitudes and phases of the seasonal variation shed light on the coupling of stratospheric regions to each other. In particular, the Northern mid-latitude stratosphere is well coupled to the tropics, while the Northern lowermost mid-latitudinal stratosphere is decoupled, confirming the separation of the shallow branch of the Brewer-Dobson circulation from the deep branch. We suggest an overall increased tropical upwelling, together with weakening of mixing barriers, especially in the Northern Hemisphere, as a hypothetical model to explain the observed pattern of linear multi-year increase/decrease, and amplitudes and phase shifts of the seasonal variation.
\end{abstract}

\section{Introduction}

The increase of greenhouse gas abundances in the atmosphere is associated with an increased radiative forcing, leading to a warming of the troposphere and a cooling of the stratosphere (IPCC, 2007). A secondary effect of increasing levels of greenhouse gases is a possible change in the stratospheric circulation (Butchart et al., 2006) with substantial feed-backs on chlorofluorocarbon lifetimes (Butchart and Scaife, 2001; Douglass et al., 2008), ozone (Shepherd, 2008) and the climate system (Baldwin et al., 2007). Model calculations (Waugh and Hall, 2002) have shown that the mean age of air in the stratosphere is a good indicator of the strength of the residual circulation ( $\mathrm{Li}$ and Waugh, 1999) and that mean age is expected to decrease in chemistry-climate models prescribing increases in long-lived greenhouse gases (Austin et al., 2007; Austin and Li, 2006; Garcia and Randel, 2008; McLandress and Shepherd, 2009; Oman et al., 2009; SPARC CCMVal, 2010). An increase in the rate of up-welling in the tropical lower stratosphere is predicted by all atmospheric general circulation models (Butchart et al., 2006) and is consistent with the observed long term temperature decrease in the tropical tropopause region (Thompson and Solomon, 2005). The models suggest that a change in the mean age of air has occurred over the past $40 \mathrm{yr}$, with a decrease of mean age mainly occurring after 1975, coupled to an increase in mean tropical upwelling. Most models derive a decrease in the range of -0.20 to $-0.05 \mathrm{yr}_{\text {decade }}-1$ (Waugh, 2009).

Based on meteorological data, positive anomalies in tropical upwelling have also been derived for the period from 2001 to 2004 when compared to the long term mean (Randel et al., 2006). An extended study using tropical ozone data from SAGE II and the SHADOZ ozonesonde network for 
the years 1984 to 2009 detected negative ozone trends consistent to systematic increases in tropical stratospheric upwelling (Randel and Thompson, 2011). A drop in tropical lower stratospheric water vapor in the year 2000 with persistently lower values in the following years has also been linked to colder tropopause temperatures due to increased tropical upwelling (Rosenlof and Reid, 2008; Solomon et al., 2010; Dhomse et al., 2008). If this increased upwelling also leads to an increase in the overall residual circulation of the stratosphere (Brewer-Dobson circulation), then shorter transport times and shorter residence times of some greenhouse gases and ozone-depleting substances (ODS) are expected, as these are mainly photolysed at altitudes above $20 \mathrm{~km}$ in the tropics, leading to decreased atmospheric lifetimes. An increased upwelling which is restricted to the lowest part of the tropical stratosphere, however, would have a much smaller feed-back on the lifetimes of ODSs.

The studies above indicate that a change in the mean circulation may occur, which could lead to changes in mean age and may have a strong impact on the overall composition of the stratosphere. The mean age is perhaps the most suitable tracer to detect such changes in atmospheric coupling. As the expected changes in mean age over 5 decades are reported to be in the order of 10\% (2010-2100) to 20\% (1960-2010) only (Austin and Li, 2006), they are difficult to detect from observations, which are influenced by atmospheric variability and by systematic errors in the derivation of mean age.

Mean age can be derived from observations of tracers which increase with time in the atmosphere and show neither sinks nor sources in the middle atmosphere. The two tracers that have been used most widely to derive mean age are carbon dioxide $\left(\mathrm{CO}_{2}\right)$ and sulfur hexafluoride $\left(\mathrm{SF}_{6}\right)$ (Boering et al., 1996; Andrews et al., 2001; Elkins et al., 1996; Ray et al., 1999; Harnisch et al., 1996; Hall et al., 1999; Patra et al., 1997; Schmidt and Khedim, 1991). Both of these tracers have somewhat different characteristics: $\mathrm{CO}_{2}$ has a seasonal cycle in the troposphere which can propagate into the stratosphere and makes the determination of mean age values below $2 \mathrm{yr}$ ambiguous. It also has a stratospheric source due to the oxidation of methane and the reaction $\mathrm{CO}+\mathrm{OH}$, which can however be corrected for if methane is measured simultaneously. Furthermore, the growth rate of $\mathrm{CO}_{2}$ shows considerable interannual variability, as it is strongly coupled to the biosphere. Such interannual variability may lead to systematic uncertainties in the dating of the air. $\mathrm{SF}_{6}$, on the other hand, increases monotonically and with small interannual variability in the troposphere but has a sink in the mesosphere, which can cause an artefact when dating old air (Waugh and Hall, 2002; Strunk et al., 2000; Reddmann et al., 2001; Engel et al., 2002, 2006; Ray et al., 2002; Plumb et al., 2002; Stiller et al., 2008).

When age of stratospheric air was first discussed, it was defined "relative to the date when the measured stratospheric ... content was observed in the troposphere" (Schmidt and Khedim, 1991; Solomon, 1990). Later it was defined as time lag since the air parcel had passed the tropopause (Hall and Plumb, 1994). The slow ascent of the air through the tropical transition layer (TTL) (e.g. Fueglistaler et al., 2009), however, was not considered then, and based on the assumption that the troposphere is well mixed, surface measurements of the age tracer were taken as a reference. Today we know that the air needs considerable time of the order of weeks up to months to travel through the TTL (Strahan et al., 1998; Park et al., 2007; Chen et al., 2012), the Hall and Plumb (1994) definition of the age of stratospheric air, however, requires reference measurements of the age tracer at the tropopause, i.e. at the upper boundary of the TTL. These are usually not available. Since a model diagnostic which cannot be measured is of limited use for model validation, we are forced to use a slightly modified definition of the age of air, which is the time lag since the air parcel has left the well-mixed part of the troposphere and entered the TTL. This modified definition leads to age of air estimates which are up to half a year older than those referring to the tropopause as reference point. This modified definition offers three advantages: (1) we avoid any adjustment of the age of air to the old definition on the basis of subtracting the expected TTL transition time, which is an uncertain quantity in itself; (2) our age estimates are directly comparable to those of other measurements, almost all of which use surface reference data, because the troposphere below the TTL is well-mixed; and (3) we avoid any low bias of the age of air estimates which could be caused by lateral mixing of old air with that at the entry point at the stratosphere, which would lead to too low mixing ratios of the age tracer in the reference measurement.

The only long-term observational data set on age of air available so far, provided by Engel et al. (2009) and covering the years 1975 to 2005, did not confirm model results predicting the decrease in age of air. The authors derived an increase of $+0.24 \pm 0.22(1-\sigma) \mathrm{yr} \mathrm{decade}^{-1}$ for Northern mid-latitudes over the period of 1975 to 2005 , which is inconsistent to the upper limit of the model predictions $\left(-0.25 \mathrm{yr} \mathrm{decade}^{-1}\right)$ on a confidence level of $95 \%$, while the lower end of the predictions $(-0.08 \mathrm{yr}$ per decade) could not be falsified on the $95 \%$ confidence level.

Recent publications (e.g. Garcia et al., 2011) argue that a data set as sparse as the Engel et al. (2009) time series was not useful for estimating a decadal trend, supporting this statement with similar sampling exercises on their model results. These authors emphasis the need for well-sampled observations of strictly linearly growing tracers which, as they state, are not available.

In this paper, we present observations of $\mathrm{SF}_{6}$ by the MIPAS satellite instrument from which stratospheric mean age of air is derived. Section 2 describes the measurements and the retrieval procedure to derive $\mathrm{SF}_{6}$. In Sect. 3, the derivation of mean age of stratospheric air from the observed global fields of $\mathrm{SF}_{6}$ is described, and global distributions of mean age of air will be presented. 
In Sect. 4, we present the multi-parameter linear regression approach which has been applied to the MIPAS data set covering September 2002 to January 2010 in order to derive a quantitative description of the temporal variation of age of air over latitudes and altitudes. In Sect. 5, these methods are applied to MIPAS age of air data for analysis of seasonal and long-term variation for each latitude and altitude. The impact of model errors and data autocorrelation is assessed in Sect. 7. In Sect. 8 we summarise the results in the light of possible changes of the Brewer-Dobson circulation.

\section{MIPAS measurements and data}

The Michelson Interferometer for Passive Atmospheric Sounding (MIPAS) is a Fourier-Transform Infrared Spectrometer with high spectral resolution which was launched into a sun-synchroneous orbit aboard the Environmental Satellite (Envisat) on 1 March 2002. From 2002 to March 2004 it provided about 1000 limb sequences of midinfrared radiance spectra per day along 14.4 orbits in the 4.15 to $14.6 \mu \mathrm{m}$ range with a spectral resolution of $0.035 \mathrm{~cm}^{-1}$, a vertical sampling of $3 \mathrm{~km}$ in the upper troposphere and stratosphere range, and a horizontal sampling of $510 \mathrm{~km}$ alongtrack (Fischer et al., 2008). The instantaneous field of view covers $3 \mathrm{~km}$ in the vertical and $30 \mathrm{~km}$ in the horizontal direction. After a problem with the interferometer slide, which caused an interruption of operation, MIPAS resumed measurements in January 2005 with slightly degraded spectral $\left(0.0625 \mathrm{~cm}^{-1}\right)$ but improved spatial resolution (vertical sampling $1.5 \mathrm{~km}$ up to $22 \mathrm{~km}$, increasing to $3 \mathrm{~km}$ in the upper stratosphere, sampling along-track between 275 and $410 \mathrm{~km}$ depending on observation mode).

Vertical profiles of $\mathrm{SF}_{6}$ were retrieved from the measurements of the first operation period (September 2002 to March 2004, ESA data version 4.61/4.62) from the spectral signature near $948 \mathrm{~cm}^{-1}$ as described by Stiller et al. (2008). The slightly degraded spectral resolution of the MIPAS operation mode since January 2005 (ESA data version 4.67) required some adjustment of the retrieval set-up. An extended spectral range from 941.0 to $952.0 \mathrm{~cm}^{-1}$ was used for the retrieval in order to have more independent information on lines of other species at the reduced spectral resolution. The improved vertical sampling, however, allowed for a relaxation of the vertical regularization within the Tikhonovconstrained global-fit approach (Tikhonov, 1963; Steck and von Clarmann, 2001). Radiance measurements up to $41 \mathrm{~km}$ tangent altitude were used within the retrieval.

The adjusted retrieval set-up resulted in vertical profiles of $\mathrm{SF}_{6}$ covering the 6 to $40 \mathrm{~km}$ altitude range with typical measurement noise errors of 10 to $20 \%$ (single scan). The total precision, including all randomly varying parameter errors has remained similar to observations of the first MIPAS mission period and is estimated at 10 to $40 \%$ (single scan) (Stiller et al., 2008). For comparison, the standard deviation (standard error) of the daily zonal mean covering a $5^{\circ}$ latitude bin is in the range of 8 to $16 \%$ ( 1 to $2 \%$ ), including both the total precision of the measurements and the natural variability within the latitude band. The standard error of the mean (SEM) of a single daily $10^{\circ}$ latitude $/ 1 \mathrm{~km}$ altitude bin, translates into an uncertainty of age of air for this bin in the order of 0.1 to $0.2 \mathrm{yr}$, while SEMs of monthly means, which are the relevant data uncertainties in all following analysis, are 0.02 to $0.03 \mathrm{yr}$.

Systematic errors not varying in sign with time and thus potentially contributing to a systematic bias were estimated at about $6 \%$ (Stiller et al., 2008), resulting in a total accuracy of a single profile (summing up all random and systematic errors according to Gaussian error propagation) of 12 to $40 \%$. The vertical resolution of the profiles is $4 \mathrm{~km}$ (up to $20 \mathrm{~km}$ altitude) to $6 \mathrm{~km}$ (at $30 \mathrm{~km}$ altitude), increasing to $8 \mathrm{~km}$ at $40 \mathrm{~km}$ and above. MIPAS $\mathrm{SF}_{6}$ profiles have been validated versus measurements of a balloon-borne cryogenic whole-air sampler (Engel et al., 2006), and agreement within $0.5 \mathrm{pptv}$, consistent to our precision estimate for single profiles, has been found for close coincidences and similar air masses (in terms of potential vorticity) sampled (Stiller et al., 2008). Later in this paper (Sect. 4) we show that age of air derived from our data is within approximately $0.3 \mathrm{yr}$ of age of air derived from balloon-borne cryogenic whole-air sampler measurements; this proves that the deviations in the range of $0.5 \mathrm{pptv}$ are indeed precision limits which can be improved by averaging over larger data amounts, since a systematic bias of 0.5 pptv would result in an age of air difference of about 2 yr.

For more details on the retrieval procedure and the estimation of random and systematic errors we refer to Stiller et al. (2008). The calibration insufficiency reported there was no more present in ESA version 4.67 spectral data provided since January 2005 . Thus, the correction scheme described in Stiller et al. (2008) needed no longer to be applied to $\mathrm{SF}_{6}$ profiles measured in the years 2005 to 2010. Since this scheme was a first-order correction only, some scatter in the time series introduced by the time-dependent calibration insufficiency remained which is not present in the 2005 to 2010 data set. Spectral data from both the nominal observation mode (covering 6 to $70 \mathrm{~km}, \mathrm{NOM}$ ) and the UTLS observation mode (covering 5.5 to $50 \mathrm{~km}$ ) have been used, and the same retrieval set-up could be applied, since for altitudes relevant to this paper both observation modes are equivalent. Figure 1 provides the time series of $\mathrm{SF}_{6}$ volume mixing ratio over all latitudes at $25 \mathrm{~km}$ altitude. The continuous growth of $\mathrm{SF}_{6}$ at all latitudes, but also seasonal and other temporal variations are clearly seen. Over all, more than $10^{6}$ retrieved profiles of $\mathrm{SF}_{6}$ covering the period September 2002 to end of January 2010, have been combined to the data set analysed further in this paper. 


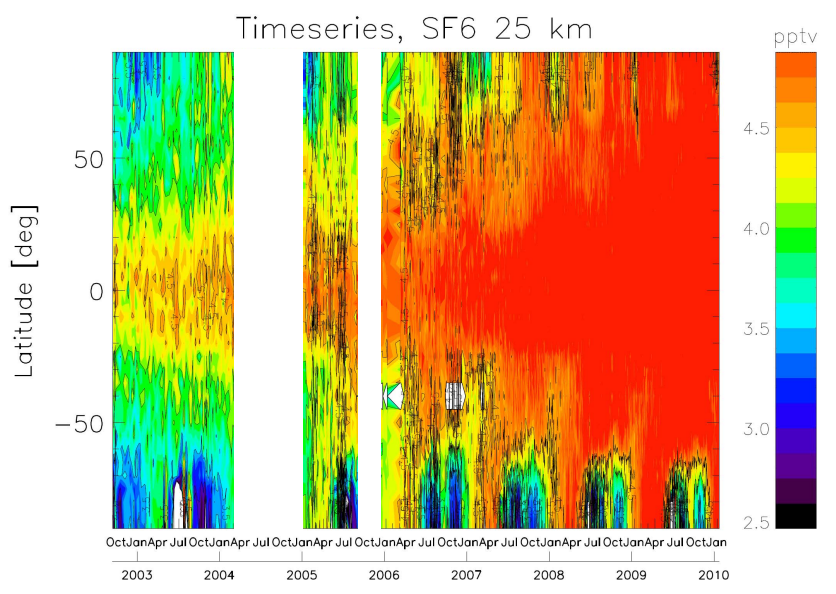

Fig. 1. Time series of $\mathrm{SF}_{6}$ volume mixing ratio over all latitudes at $25 \mathrm{~km}$ altitude for the period September 2002 to January 2010. The white bars indicate data gaps where no measurements were available.

\section{Tropical tropospheric increase of $\mathrm{SF}_{6}$ and conversion into age of air}

The age of stratospheric air (AoA) is derived from a stable tracer of a monotonically increasing mixing ratio by comparison of its actual stratospheric mixing ratio with a time series of tropospheric mixing ratios. The time lag between the date of the stratospheric measurement and the time when the same mixing ratio was measured in the troposphere is commonly defined as the mean age of air. For this analysis, the comparability of tropospheric data and the MIPAS measurements has been tested and a systematic bias between the two MIPAS subsets has been found and corrected for (Sect. 3.1), and a tropospheric reference curve reflecting the $\mathrm{SF}_{6}$ increase with time was constructed (Sect. 3.2). Mixing of stratospheric air along with a nonlinear reference curve requires a correction (Sect. 3.3), before reliable age of air distributions can be calculated (Sect. 3.4).

\subsection{Comparison of tropical free troposphere data to ground-based in situ data}

Daily mean mixing ratios of $\mathrm{SF}_{6}$ in the region of the upper tropical troposphere within 9 to $15 \mathrm{~km}$ altitude and from $17.5^{\circ} \mathrm{S}$ to $17.5^{\circ} \mathrm{N}$ as function of time were derived from MIPAS observations and compared both to $\mathrm{SF}_{6}$ global monthly means from the National Oceanic and Atmospheric Administration, Earth System Research Laboratory (NOAA/ESRL) halocarbons program retrieved from ftp://ftp.cmdl.noaa.gov/ hats/sf6/combined/HATS_global_SF6.txt. The MIPAS data for this altitude-latitude bin belong to the tropical free troposphere below the tropical transition layer (TTL). Transport times from the ground to the lower boundary of the TTL are in the order of days only (Strahan et al., 1998) due to rapid convective processes. For this reason, we do not expect a significant delay between ground-based and free tropospheric $\mathrm{SF}_{6}$ mixing ratios. The data set from NOAA/ESRL is a combination from two measurement programs. Weighted averages of monthly mean data are combined, interpolated, and smoothed for each sampling location. Hemispheric and global means are estimated by cosine weighting by latitude (see Hall et al., 2011, for more details). Further, MIPAS data were compared to in situ ground-based observations in the tropics (Mauna Loa Observatory and American Samoa) (Elkins and Dutton, 2009; Rigby et al., 2010; Hall et al., 2011) (see Fig. 2, top panel). The MIPAS SF 6 volume mixing ratios from the upper tropical troposphere compare well with both the in situ ground-based tropical data and the combined flask/in situ global means. In particular, the temporal evolutions of all data sets demonstrate that, as already reported by Levin et al. (2010), Rigby et al. (2010), and Hall et al. (2011), tropospheric $\mathrm{SF}_{6}$ volume mixing ratios have started to grow clearly stronger than linear in 2006, with continuously increasing growth rates until 2009. A closer look to the consistency of all data sets is provided in Fig. 2, lower panels. The daily mean deviations between MIPAS tropical upper tropospheric $\mathrm{SF}_{6} \mathrm{vmr}$ and the three combined or in situ data sets reveal that:

i. a systematic bias of $(-0.111 \pm 0.013)$ pptv exists between the MIPAS 2002-2004 and 2005-2010 data sets (2005 to 2010 period being lower), determined consistently from all three combined or in situ observational data sets;

ii. the MIPAS 2002 to 2004 data set agrees best with the combined global mean data, with a bias of only $-0.013 \mathrm{pptv}$ to this data set;

iii. MIPAS $\mathrm{SF}_{6}$ is lower than the Mauna Loa Observatory data which represent the Northern Hemisphere tropics $\left(19.539^{\circ} \mathrm{N}, 155.578^{\circ} \mathrm{W}\right.$, elevation: $\left.3397 \mathrm{~m}\right)$, and higher than the American Samoa data which represent the Southern Hemisphere tropics $\left(14.3^{\circ} \mathrm{S}, 170.6^{\circ} \mathrm{W}\right.$, elevation: $77 \mathrm{~m}$ ), reflecting the bias between Northern and Southern Hemisphere due to the transport barrier.

All in all MIPAS tropical upper troposphere $\mathrm{SF}_{6} \mathrm{vmr}$ can be considered representative for the tropics; any difference between the ground-based data and the upper troposphere MIPAS data is below or, at most, similar to the accuracy of the MIPAS daily mean data; further, with transport times of hours to days from the ground to the free upper troposphere we do not expect any significant delay of upper tropospheric $\mathrm{SF}_{6}$ vmrs compared to the values at the ground. For all data used in the following work, the systematic bias between the 2002-2004 and 2005-2010 MIPAS data set has been corrected for by increasing all 2005 to 2010 data by $0.111 \mathrm{pptv}$ at all altitudes and latitudes. This is probably an oversimplified approach, but the best we can do at that time. Later, however, it will turn out (see Sect. 4.1) that despite the correction of the 2005 to 2010 data set described here, residual 


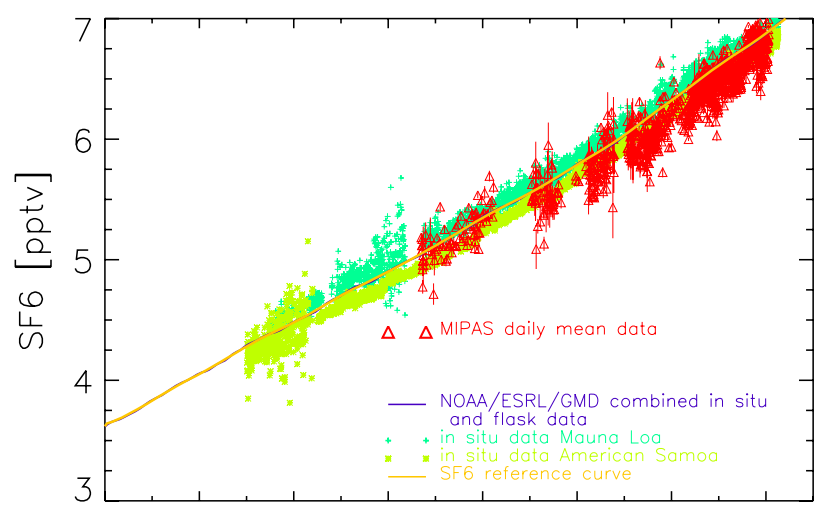

19961998200020022004200620082010 Time [year]
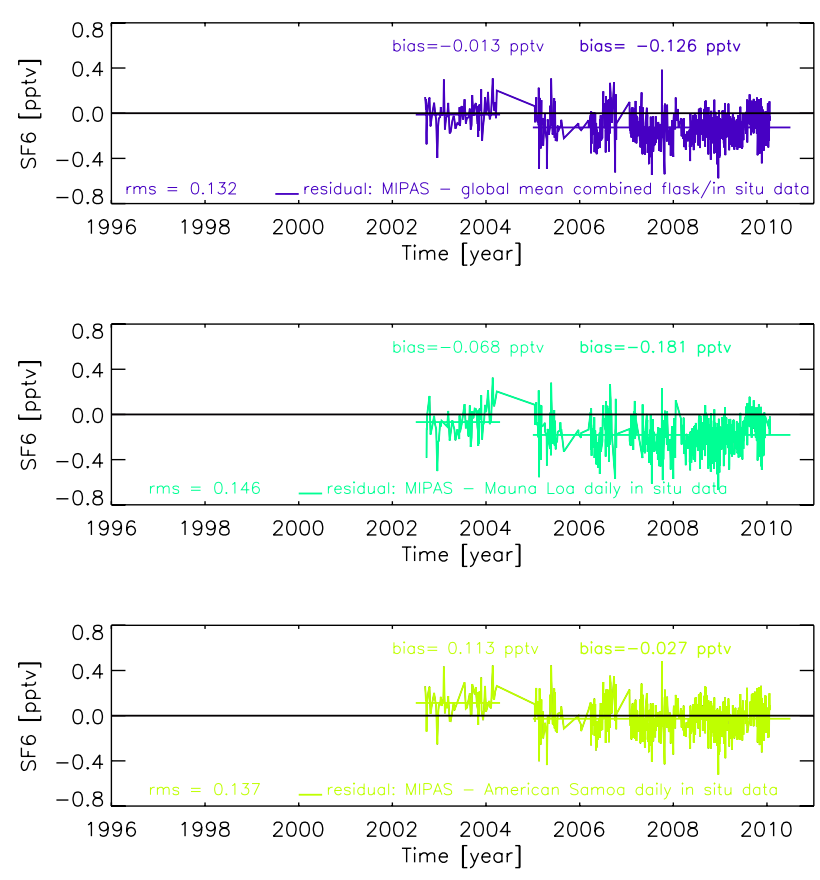

Fig. 2. Top panel: tropical upper tropospheric time series of $\mathrm{SF}_{6}$ from MIPAS observations (daily zonal averages between $17.5^{\circ} \mathrm{S}$ and $17.5^{\circ} \mathrm{N}$ and 9 to $15 \mathrm{~km}$ altitude; red triangles) together with monthly global mean combined flask and in situ data (violet line, hard to see), Mauna Loa Observatory daily mean in situ observations (dark green crosses), and American Samoa daily mean in situ observations (light green asterisks). The solid orange curve presents the $\mathrm{SF}_{6}$ tropical reference curve derived as described in the text. Bottom panel: daily mean deviations between MIPAS tropical upper tropospheric $\mathrm{SF}_{6}$ volume mixing ratios and the monthly global mean combined flask and in situ data set (top), Mauna Loa Observatory daily mean in situ observations (middle), and American Samoa daily mean in situ observations (bottom). Numbers in the panels provide the rms over the whole MIPAS observation period, and the mean bias between MIPAS $\mathrm{SF}_{6} \mathrm{vmr}$ and the respective flask and/or in situ observations for the periods 2002 to 2004 and 2005 to 2010, respectively. biases depending on latitude and altitude remained which had to be accounted for in further analysis of the data set.

\subsection{Reference curve}

According to Hall and Plumb (1994), reference $\mathrm{SF}_{6}$ abundances at the entry point to the stratosphere, i.e. the tropical tropopause region, would be needed for calculation of mean age of air from observed $\mathrm{SF}_{6}$ distributions in the stratosphere. However, long-term observational reference data which reach into the past far enough to calculate ages of many years from them, are available from ground-based observations only. The transport time through the troposphere, on the other hand, is assumed to be in the order of weeks to months, with a fast transport of several days up to lower boundary of the TTL, and a slow transport from the lower boundary of the TTL to the tropopause. In a recent study, Chen et al. (2012) have derived, from Lagrangian transport calculations, transport times of few days up to 7 weeks for air parcels from the tropical boundary layer to reach the tropopause in the Asian monsoon system; they further found that the actual transport times depend very much on the role of (overshooting) convection within the transport process.

Similar to almost all other observational data, we referred to the ground-based observational data record for calculation of the mean age of stratospheric air, accepting that this is not in strict accordance to the definition of the age of air in the modelling community (Hall and Plumb, 1994; Waugh and Hall, 2002). This choice may produce a high bias in our mean age of air data of several days to weeks or even months relative to a reference to the tropopause, equivalent to the transport time from the tropical boundary layer to the tropical tropopause. This potential high bias relative to AoA values based on the stratospheric entry-point definition should be kept in mind when comparing to modelled age of air data for which age has been set to zero at the time of tropopause crossing. Given that all except one other observational data sets refer to ground-based reference data, and the actual transport time through the troposphere is unknown, can vary with time, and is still highly uncertain, we have not attempted to transfer our data set to a reference point at the tropical tropopause.

We have constructed the $\mathrm{SF}_{6}$ reference curve from independent observations from the NOAA/ESRL data sets: for the period 1996 to May 2011 we used a smoothed time series of monthly global mean combined flask and in situ data as described in Hall et al. (2011) (smoothed by an 11-months running mean, violet solid line in Fig. 2, widely overlaid by the orange curve), while for the period 1987 to 1996 we used the linear approximation $y=0.125+0.215 \times(t-1985)$ as provided by Hall et al. (2011). Since MIPAS measurement uncertainties may lead to $\mathrm{SF}_{6}$ volume mixing ratios slightly larger than the highest abundances in the reference data set, which will result in negative age of air values, an extension to data beyond January 2010 was necessary. We have used a 
linear extrapolation with the averaged slope of the last year of the NOAA/ESRL data for this purpose. The reference curve is shown as orange line in Fig. 2.

\subsection{Non-linearity correction}

If the tropospheric trend of $\mathrm{SF}_{6}$ was exactly linear, the determination of the mean age of stratospheric air would be an almost trivial task: the linear regression function representing the tropospheric mixing ratio as a function of time could easily be inverted and the age of the sounded air parcel could be calculated as the time lag $\Delta t$ between the date of the measurement $t$ and the date in the past $t^{\prime}$ when the measured mixing ratio was found in the troposphere. Even the fact that the sounded air parcel had been subject to mixing processes would not cause major difficulties because, due to the linear relationship between tropospheric $\mathrm{SF}_{6}$ mixing ratio and time, the measured mixing ratio in an air parcel would still represent the mean age of air, regardless what the age distribution within the air parcel might be (e.g. Waugh and Hall, 2002). Unfortunately, the tropospheric mixing ratio of $\mathrm{SF}_{6}$ is a slightly nonlinear function of time, and a more sophisticated approach is needed. In agreement with literature (e.g. Andrews et al., 1999) we describe the age spectrum by a Green's function $G$. As shown in several studies (Waugh and Hall, 2002), the Green's function of a one-dimensional model can already approximate the Green's function of the real stratosphere quite well. This particular Green's function can be represented by a Wald (inverse Gaussian) function

$G\left(\Gamma, \Delta, t^{\prime}\right)=\frac{1}{2 \Delta \sqrt{\pi t^{\prime 3}}} \exp \left[\frac{-\Gamma^{2}\left(t^{\prime}-1\right)^{2}}{4 \Delta^{2} t^{\prime}}\right]$

with $\Gamma$ being the mean age of stratospheric air, $t^{\prime}=\Delta t / \Gamma$, $\Delta t$ the transit time of an air parcel from the stratospheric entry point at the tropical tropopause to the relevant location in the stratosphere, and $\Delta$ being the width of the distribution. For $\Delta$ we use the approximation according to Waugh and Hall (2002)

$w=\Delta^{2} / \Gamma=$ constant $\approx 0.7$.

In a first step of our iterative approach we determine a first guess of the age of the air parcel by simply mapping the measured $\mathrm{SF}_{6}$ mixing ratio onto the time axis. For this initially guessed age we determine the width $\Delta$ of the age spectrum using the relation in Eq. (2) and apply the spectrum to the tropospheric $\mathrm{SF}_{6}$-time relationship (Fig. 2, top panel) to give the $\left[\mathrm{SF}_{6}\right]_{\text {modeled }}$, which is the $\mathrm{SF}_{6}$ mixing ratio which would correspond to the initially guessed age of the sounded air parcel:

$\left[\mathrm{SF}_{6}\right]_{\text {modeled }}=\int_{t} G(\Gamma, \Delta, t) \cdot\left[\mathrm{SF}_{6}\right]_{\text {trop }}(t) \mathrm{d} t$

The residual $\left[\mathrm{SF}_{6}\right]_{\text {modeled }}-\left[\mathrm{SF}_{6}\right]_{\text {measured }}$ and the inverse first derivative $\left(\mathrm{d}_{[}\left[\mathrm{SF}_{6}\right]_{\text {trop }} / \mathrm{d} t\right)^{-1}$ of the tropospheric $\mathrm{SF}_{6}$-time relationship allow to determine the actual mean age of the measured air parcel by Newtonean iteration. The correction is not strictly monotonically increasing with age due to the variations in the $\mathrm{SF}_{6}$ reference curve (smoothed combined flask and in situ observations). The difference of the initially guessed age and the final result, i.e. the effect of the age spectrum and the nonlinearity of the tropospheric $\mathrm{SF}_{6}$-time relationship ranges from -0.1 to $0.2 \mathrm{yr}$ for ages between 0 and $10 \mathrm{yr}$, and up to $0.8 \mathrm{yr}$ for ages higher than $10 \mathrm{yr}$. This is in good agreement to results derived by Volk et al. (1997), who assessed the necessary correction of age of air calculation for the case of quadratic increase. Although a correction of up to $0.8 \mathrm{yr}$ seems to be considerable, almost nothing changed at the relative patterns and variations of global age of air distributions as presented in the next section.

The assumption that the width of the age spectrum $\Delta$ is given by $w=\Delta^{2} / \Gamma=$ const. $\approx 0.7$ which has been used in the correction procedure described above does certainly not strictly hold for all altitude/latitude regions of the stratosphere. On the other hand, little is known on realistic age spectra and their variation from observations (cf. Schoeberl et al., 2005), so that $w=0.7$ seems to be an acceptable approximation for the moment. Model assessments result in a variation of $w$ between 0.4 and $1.5 \mathrm{yr}$ (Hall and Plumb, 1994; Waugh et al., 1997; Volk et al., 1997). Therefore we have tested the non-linearity correction with the width parameter $w=1.5$ as well, but did not find significant differences for the overall age of air distributions, their patterns and variations.

\subsection{Global distribution and temporal evolution of age of air}

The method described in the previous section was used to derive monthly zonal means of mean age of stratospheric air from the MIPAS $\mathrm{SF}_{6}$ observations. $\mathrm{SF}_{6}$ individual profiles have been averaged per month over $10^{\circ}$ latitude bins on the altitudes of the retrieval grid to derive monthly zonal means. Data outside the altitude range actually seen by MIPAS (e.g. due to cloud contamination) or of low information content have been omitted. The $10^{\circ}$ ensembles of binned AoA profiles have typically a standard deviation of 0.6 to $1.2 \mathrm{yr}$, including both random data uncertainties and natural variability. The standard errors of the mean (SEM) of daily $10^{\circ}$ zonal means are in the order of 0.1 to $0.2 \mathrm{yr}$, while the SEM of monthly zonal means are 0.02 to 0.03 yr. These errors cover random measurement uncertainty and natural variability of the averaged ensembles only. Systematic errors might be present as well which cannot be reduced by averaging; Stiller et al. (2008) have assessed them to be in the order of 0 to $-0.5 \mathrm{yr}$ in the lower stratosphere and up to $+1 \mathrm{yr}$ above $25 \mathrm{~km}$, thus varying with latitude and altitude, but not with time. Since for the further work we are interested in the temporal evolution of mean age of air at fixed altitude/latitude bins, these systematic errors, although large compared to the SEM, will not affect our analysis. 
While for the first period of MIPAS observations (2002 to 2004) the temporal coverage is still fairly sparse (about 3 to 10 days per month), the second period was almost completely analysed and daily zonal mean age of air data are available for all measurement days in the NOM and UTLS mode of MIPAS.

For a first overview of the global mean distribution of AoA and its seasonal variation we have built multi-year seasonal zonal averages (Fig. 3). As expected, AoA is lowest in the lower tropical stratosphere and increases with altitude and latitude. Zero AoA is found in the tropical troposphere below $16 \mathrm{~km}$, consistent to our reference point, the tropical troposphere just below the TTL. An area of younger air always appears in the zonal mean data in the upper tropical stratosphere between 35 and $40 \mathrm{~km}$ for which we do not have a proper explanation yet; in any case, if such a constricted area of younger air exists in zonal mean data, this must be a convergence zone in stratospheric transport. Polar vortex air and uppermost stratospheric air appears to be unrealisticly old; this is due to subsidence of mesospheric $\mathrm{SF}_{6}$-depleted air and will be further discussed in Sect. 4.2. The seasonal variation is dominated by changes in the outer tropics and the polar regions. During Southern hemispheric winter (JJA), the Austral polar vortex is well developed and filled with old and $\mathrm{SF}_{6}$-depleted air subsided from the mesosphere. Meridional gradients of AoA over the vortex boundary are pronounced. At the same time, a peak of young air is obvious in the lowermost stratosphere around $20-30^{\circ}$ of the winter hemisphere where $1 \mathrm{yr}$ old air reaches altitudes of $20 \mathrm{~km}$. The midlatitudinal surf zone with low meridional and vertical AoA gradients can be identified as well. Another interesting feature are two peaks of younger air in the uppermost stratosphere between 30 and $40^{\circ} \mathrm{N} / \mathrm{S}$. Over the Northern summer pole, still rather old air, indicating remnants of earlier subsidence, exists. In SON, the shape and depth of the Southern polar vortex has not changed much, while the peak of young air in the lower outer tropics is less developed. The interhemispheric distribution now is less symmetrical, with indications of uplifting of the remaining old air over the Northern polar and mid-latitudinal region. In DJF, during Northern winter and Southern summer, the Austral polar vortex has disappeared, leaving all the Southern polar and mid-latitudes with rather old air which had obviously been mixed in after the vortex break-down. The process of vortex break-down will be analyzed further in Sect. 4.2. At the same time, a peak of young air appears in the Northern outer tropical lowermost stratosphere. A continuation of the upward-northward transport might be identifiable in the isolines at Northern mid-latitudes between 30 and $40 \mathrm{~km}$ as well. The Northern polar vortex has developed, with stronger vertical AoA gradients than before, but far less pronounced than for the Southern polar vortex. In MAM, the last remnants of old ex-vortex air in the upper stratosphere over the Southern polar region are "pushed back" into the mesosphere, while in the middle stratosphere weak vertical AoA gradients dominate in both hemispheres.

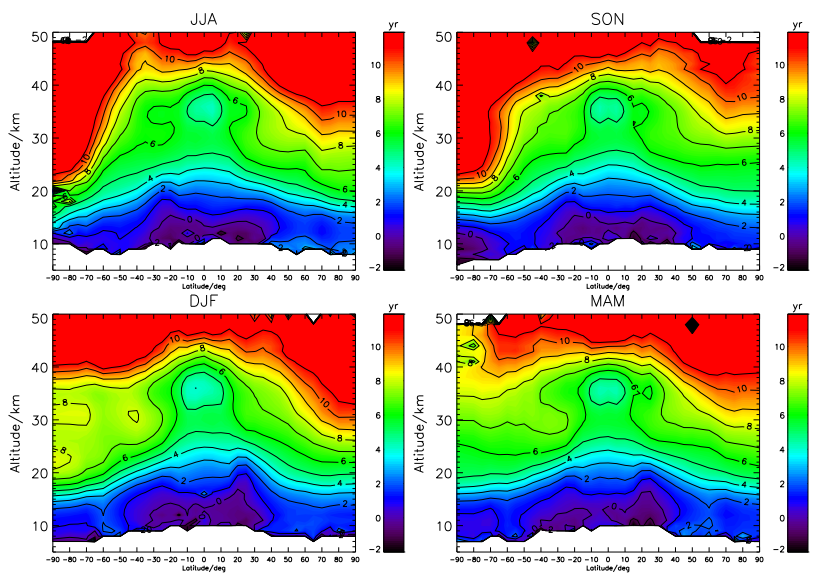

Fig. 3. Zonal mean distribution of mean age of stratospheric air for the four seasons, derived by averaging MIPAS AoA data of all available years for the respective season.

In summary, there are significant differences among the hemispheres, dominated by the different development of the polar vortices, while similarities exist as well: the vortex break-down and uplift of remnants of old air happens immediately before the onset of the next vortex formation during the (late) fall months in both hemispheres. The seasonal variation of the Brewer-Dobson circulation can be identified at the uplifting of very young air in the outer tropics during hemispheric winter (although more pronounced in the Northern Hemisphere) and the subsequent upward/poleward transport, leading to the mid-latitudinal surf zones. The overturning circulation appears as a seesaw lifting air in late polar summer, and subsiding air in subsequent fall and winter. A more detailed view of the seasonal and multi-annual variation is provided as an animation in the Supplement.

In order to put the observed global distributions of AoA into context of earlier observations, a latitudinal cross section of AoA has been compared with observational data measured in the 1990s (see Fig. 4). The figure provides MIPAS AoA latitudinal cross-sections at $20 \mathrm{~km}$ for selected months, together with the total AoA range covered by all monthly mean data from MIPAS (derived from the minimum and maximum values for each latitude bin), and the AoA derived from airborne measurements of $\mathrm{SF}_{6}$ and $\mathrm{CO}_{2}$ as published by Waugh and Hall (2002). The airborne measurements are from NASA ER-2 high-altitude aircraft as well as balloon flights covering various latitudes and seasons in the years 1992 to 1998 (Boering et al., 1996; Elkins et al., 1996; Ray et al., 1999; Andrews et al., 2001). It should be noted that the AoA from $\mathrm{CO}_{2}$ observations is derived by referring to $\mathrm{CO}_{2}$ at the tropical tropopause (Andrews et al., 1999), and might be somewhat lower than $\mathrm{SF}_{6}$-derived AoA for this reason. The data from the individual aircraft and balloon campaigns have been compiled to provide a latitudinal cross-section by Hall et al. (1999). 


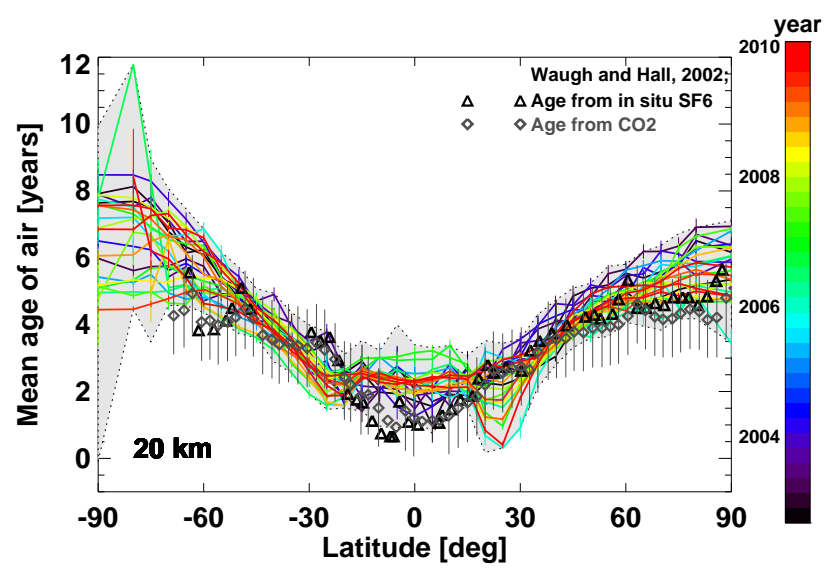

Fig. 4. Comparison of MIPAS AoA latitude cross-sections at $20 \mathrm{~km}$ altitude (colored curves and shaded area) with AoA derived from earlier airborne $\mathrm{SF}_{6}$ (black triangles) and $\mathrm{CO}_{2}$ measurements (grey diamonds with error bars) as published in Waugh and Hall (2002) and Hall et al. (1999). The shaded area represents the range of all MIPAS monthly mean AoA observations, while the colored curves show AoA latitudinal dependence for every third month. The color code provides the time of measurement (for color coding see bar at the right).

The agreement between the MIPAS monthly zonal mean latitude cross-sections and the earlier airborne observations is excellent in the Northern and Southern mid-latitudes. Some smaller deviations occur at high and low latitudes, although still most data points of the airborne campaigns fall into the range covered by MIPAS. At high Northern and Southern latitudes, beyond $60^{\circ} \mathrm{N} / \mathrm{S}$, there might be a tendency of MIPAS data to be slightly higher than the airborne campaign data, in particular the $\mathrm{CO}_{2}$-derived $\mathrm{AoA}$ data, since the campaign data are closer to the lower boundary of the MIPAS AoA range. Regarding $\mathrm{CO}_{2}$, however, the potential low bias due to referencing to tropopause values should be kept in mind. The difference between airborne campaign data and MIPAS is more severe in the tropics. Again, the campaign data are over all closer to the lower boundary of the range covered by MIPAS, but most data points fall still in this range. The shape of the latitude cross sections of MIPAS is considerably different to that of the campaign data. While MIPAS shows a plateau of similarly old age over the inner tropics for most of the months shown, with peaks towards younger air at the boundary to the subtropics, the campaign data provide lowest AoA in the inner tropics. It should further be noted that the AoA in the tropics as observed by MIPAS shows some systematic variation over time: it started quite young (blue and violet curves, 2002 to 2005), became significantly older over the next years until 2007 (green curves), and turned to lower ages again (red curves, 2008/2009). The peaks observed near $25^{\circ} \mathrm{N} / \mathrm{S}$ are related to the peaks of young air at the subtropics as discussed for Fig. 3 and are most pronounced during hemispheric winter.

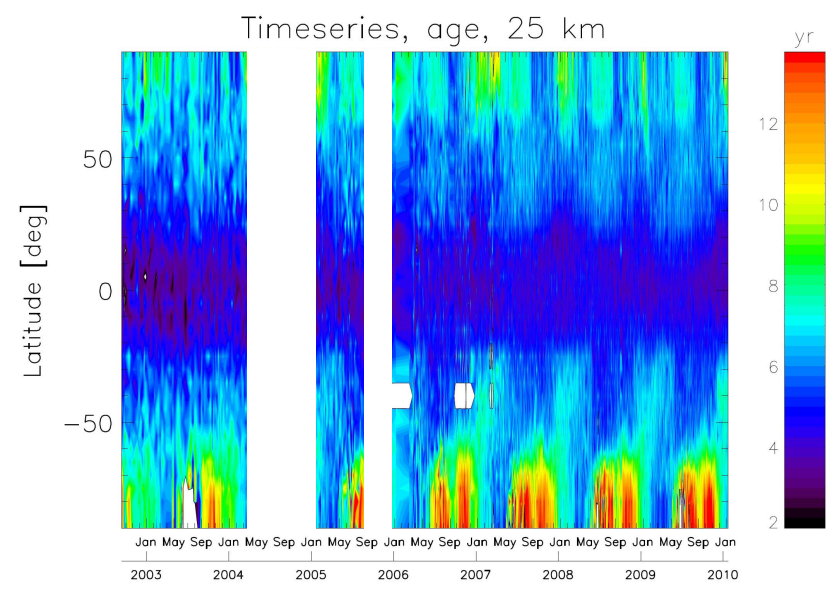

Fig. 5. Latitude-time cross-section of mean age of air at $25 \mathrm{~km}$ altitude for the period September 2002 to January 2010. White areas represent regions where no data are available.

We have currently no means to decide if the different behavior seen in tropical AoA from MIPAS and airborne campaign data, respectively, is due to artifacts in one or the other data set, or due to changes of the atmosphere over the ten to fifteen years which are in between the observations. The latter is not fully unexpected, given the observed cooling of the tropical tropopause around the year 2000 and the recovery during the following years (Randel et al., 2006) at one hand, and the observed variability over the measurement period of MIPAS at the other hand. The aircraft measurements show larger gradients in the regions of the mixing barriers. If mixing barriers have become weaker over the past years, as we will outline later as a hypothesis (see Sect. 6), tropical age of air would have increased, which is consistent to our observations. Further it must be kept in mind that the airborne measurements do not provide - as MIPAS - the latitudinal cross section at a given time, but are a composite over several years and seasons. Combining such data points to a latitudinal cross section could affect its shape considerably.

Figure 5 provides, as an overview, a latitude-time crosssection of observed age of air at an altitude of $25 \mathrm{~km}$ from pole to pole for September 2002 to January 2010. The age of air distribution reveals pronounced seasonal cycles from the subtropics to the polar latitudes, partly overlaid by a QBO signal which is more pronounced in the Southern Hemisphere than in the Northern Hemisphere. The temporal evolution of mean age of air and its dependence on latitude and altitude will be explored in the next sections. 


\section{Analysis of the temporal variation of age of air}

\subsection{Method}

Time series of monthly mean AoA at specific altitudes and for $10^{\circ}$ latitude bins have been analysed by fitting the following regression function to the data:

$$
\begin{aligned}
\operatorname{age}(t)= & a+b t+c_{1} \mathrm{qbo}_{1}(t)+d_{1} \mathrm{qbo}_{2}(t)+ \\
& +\sum_{n=2}^{9}\left(c_{n} \sin \frac{2 \pi t}{l_{n}}+d_{n} \cos \frac{2 \pi t}{l_{n}}\right)
\end{aligned}
$$

with time $t$, quasi-biennial oscillation (QBO) indices $\mathrm{qbo}_{1}$ and $\mathrm{qbo}_{2}$, and the sum of 8 sine and 8 cosine functions of the period length $l_{n}$. The first two sine and cosine functions have the periods 12 and 6 months, respectively, and represent the seasonal and the semi-annual cycle. The following 6 terms have period lengths of 3, 4, 8, 9, 18 and 24 months and are used to describe deviations of the temporal variation from a pure sine or cosine relationship, e.g. to model a more saw-tooth like seasonal variation, and to include corrections to the QBO variations. Sine and cosine of the same period length are used together to represent any phase shift of the variation. The terms $\mathrm{qbo}_{1}$ and $\mathrm{qbo}_{2}$ are the normalized Singapore winds at 30 and $50 \mathrm{hPa}$ as provided by the Free University of Berlin via http://www.geo. fu-berlin.de/met/ag/strat/produkte/qbo/index.html. qbo 1 and $\mathrm{qbo}_{2}$ are approximately orthogonal such that their combination can emulate any QBO phase shift (Kyrölä et al., 2010). Coefficients $a, b, c_{1}, \ldots, c_{9}, d_{1}, \ldots, d_{9}$ are fitted to the data using the method of von Clarmann et al. (2010), where the full error covariance matrix of mean age data $\mathbf{S}_{\mathrm{m}}$ is considered, with the squared SEM of the monthly zonal means as the diagonal terms. For the moment, covariances are only important to consider any residual bias between pre-2004 and post-2004 age measurements because of the change of the MIPAS measurements. This is because auto-correlations among single measurements which were averaged to build the daily or monthly means, and which would increase their SEMs, were small and could be neglected. Numerical experiments where model fields were sampled according to the MIPAS sampling patterns gave no evidence that standard errors of monthly zonal means calculated without consideration of auto-correlation would be systematically too optimistic (M. Toohey, personal communication, 2011). On the contrary, in the case of the sampling patterns of MIPAS full spectral resolution measurements, the average correlation coefficients of autocorrelation seem even to be negative, rendering the simplified estimates of the SEM too pessimistic.

First visual inspection of the AoA time series for certain altitude/latitude bins revealed that the data subsets for 2002 to 2004 and 2005 to 2010 were still affected by residual biases which depended on altitude and latitudes, and which had not been fully removed by the simple correction approach as described in Sect. 3.1. In our analysis approach, the residual bias can simply be treated as a fully systematic error of one data subset with respect to the other, and can thus be described in the covariance matrix as a fully correlated error component in the block associated with the respective data subset, for each time series at a certain altitude and latitude band. Tests have shown that, contrary to a simple correction of the residual bias, this method is very robust with respect to the estimate of the residual bias used to create the covariance matrix.

Consideration of the residual bias in the covariance matrix is equivalent to infer the residual bias from the data themselves using an optimal estimation scheme where the a priori variance of the residual bias equals the residual bias component in our covariance matrix (cf. von Clarmann et al., 2001). Our method, however, supports consideration of multiple error correlations of different sources without formally increasing the number of fit variables. In a later step the consideration of covariances will also be used to handle autocorrelations of fit residuals (see Sect. 7).

Further, other tests where we fitted the second data subset alone (covering the years 2005 to 2010 only) resulted in similar values for the terms in Eq. (4) as for the complete data record, but with increased uncertainties; this result proves that the implicit bias correction works as intended, and that the first data subset, although of inferior data quality and often affected by a bias relative to the second, does not spoil the fit but contributes information and reduces uncertainties. For this reason, all further analysis was based on the full data record covering the years 2002 to 2010 .

In any case, the error of the linear trend $\sigma_{\text {Trend }}$ is simply estimated by means of generalized Gaussian error propagation:

$\sigma_{\text {Trend }^{2}}^{2}=\left(\frac{\partial b}{\partial \text { age }_{1}}, \ldots, \frac{\partial b}{\partial \operatorname{age}_{n}}\right) \mathbf{S}_{\mathrm{m}}\left(\begin{array}{c}\frac{\partial b}{\partial \mathrm{age}_{1}} \\ \vdots \\ \frac{\partial b}{\partial \operatorname{age}_{n}}\end{array}\right)$

Here $\mathbf{S}_{\mathrm{m}}$ is the covariance matrix characterizing the uncertainties of the monthly mean ages including the bias between the data subsets as described above, and $\frac{\partial b}{\partial \operatorname{age}_{n}}$ are the sensitivities of the linear trend with respect to the monthly mean ages. For more details on the method we refer to von Clarmann et al. (2010).

Figure 6 shows examples of AoA time series for 4 different latitude bands and 3 altitudes. The simple model according to Eq. (4) is able to represent the observations very well in most cases. For some latitude/altitude bins, however, large residuals point towards insufficient performance of the regression model. These altitude/latitude bins (with residuals more than a factor of 10 larger than average residuals) have been omitted from the further analysis.

The fits are in general better for the data from the second mission period of MIPAS after 2005. The daily mean data of 2002 to 2004 show larger scatter, and the monthly mean data have larger SEMs and follow less clearly the model curve. 

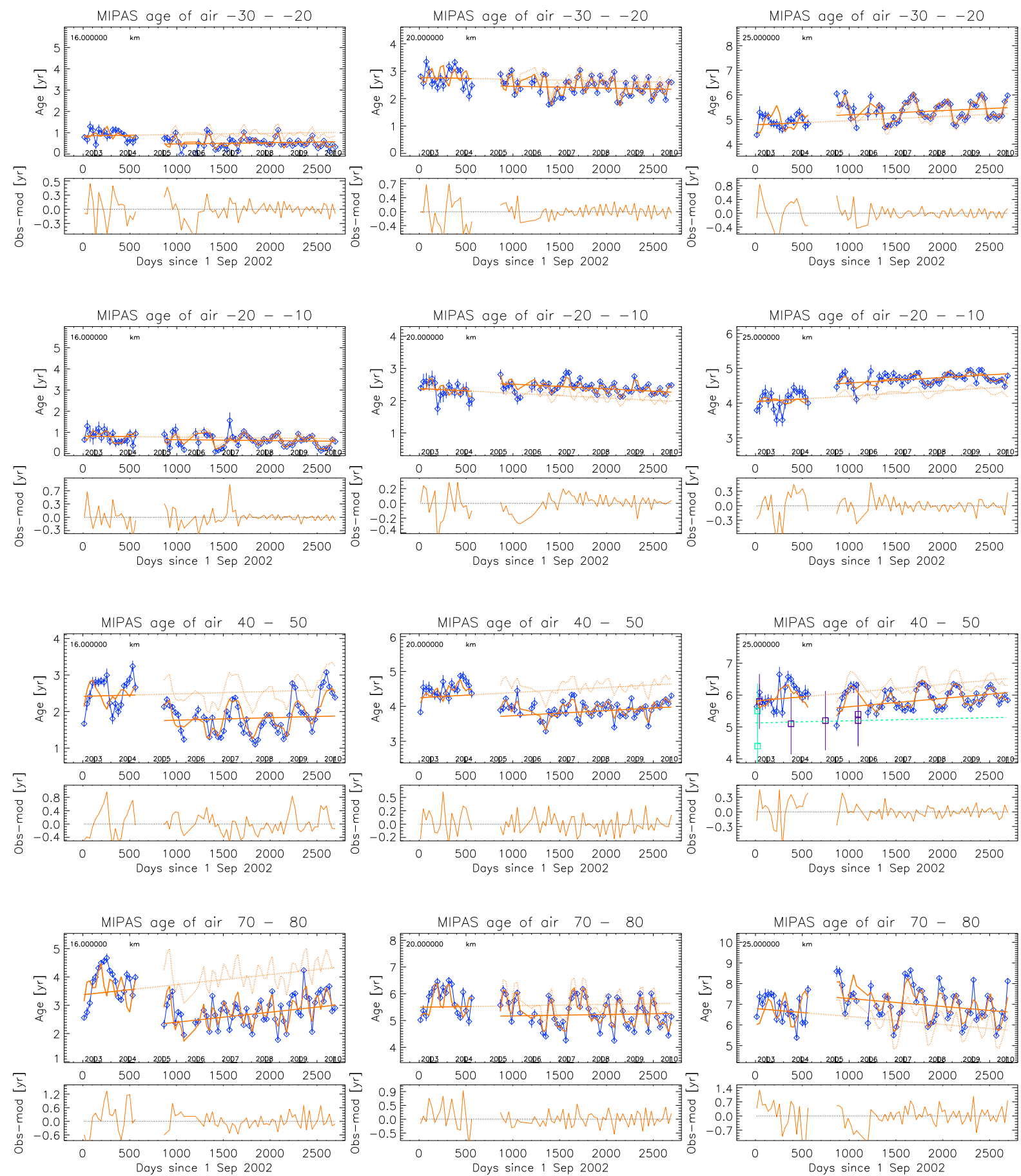

Fig. 6. Temporal evolution of age of air for the Southern subtropics $\left(30^{\circ} \mathrm{S}\right.$ to $\left.20^{\circ} \mathrm{S}\right)$ (top row), tropics $\left(20^{\circ} \mathrm{S}\right.$ to $\left.10^{\circ} \mathrm{S}\right)$ (second row), Northern mid-latitudes $\left(40^{\circ} \mathrm{N}\right.$ to $50^{\circ} \mathrm{N}$ ) (third row), and Northern polar region $\left(70^{\circ} \mathrm{N}\right.$ to $\left.80^{\circ} \mathrm{N}\right)$ (bottom row) at 3 different altitudes $(16 \mathrm{~km}$, $20 \mathrm{~km}, 25 \mathrm{~km}$ ). In the upper part of each panel, dark blue diamonds with error bars (the latter are often smaller than the diamonds and hardly visible) are the observed AoA monthly means and their SEM. The bold solid orange curve is the fit through the monthly mean data. The linear part of the regression is given as straight line. The dotted orange curve and straight line is the model without residual bias correction. In the panel for Northern mid-latitudes, $25 \mathrm{~km}$, the 30-yr AoA trend as derived by Engel et al. (2009) is included as a green dashed line, together with the data points and their uncertainties of the Engel et al. (2009) study which fall into the observation interval of MIPAS (green and violet squares, color coding of latitudes adapted to the original figure). In the lower part of each panel, the residuals between observed monthly mean AoA and the model are shown. 
Due to larger SEM of the monthly zonal means, they are considered within the regression analysis with less weight than the 2005 to 2010 data set. Recall that the 2002 to 2004 data are sparser than the data after 2005 , and were to be corrected for a calibration artefact which could be done in approximation only and adds further scatter in the temporal domain to the data set. For these reasons we consider the 2002 to 2004 data set of inferior quality than the 2005 to 2010 data set. In the future, re-processing of the data from level- $1 \mathrm{~b}$ data with corrected calibration will ultimately solve this problem.

For all altitude/latitude bins, a more or less pronounced seasonal cycle is the dominant feature of the time series. Amplitudes and phases of the seasonal variation vary considerably with latitude and altitude. These variations were confirmed by the analysis of the variability of longlived tracers like $\mathrm{CH}_{4}$ (Stiller, 2012), CFC-11 and CFC12 (Kellmann et al., 2012) and HCFC-22 (Chirkov et al., 2012) (data available at http://www.imk-asf.kit.edu/english/ 308.php). All tracers show similar seasonal variations in their abundances, in phase with the observed AoA (i.e. their abundances are highest when AoA is lowest as expected for (photo-)chemical destruction in the stratosphere), and the variation of amplitudes with latitude and altitude is similar to that of AoA. Highest amplitudes of one year or more (see Fig. 6, bottom right, and Fig. 9, top) are reached in the polar regions, while in the inner tropics, the amplitudes are low (Fig. 6, second row, and Fig. 9, top). In the Northern and Southern mid-latitudes, the amplitude of the seasonal cycle reaches a minimum around $20 \mathrm{~km}$ which seems to be a "quiet zone", with increasing amplitudes towards higher and lower altitudes (Fig. 6, first and third row, middle panels, and Fig. 9, top). The semi-annual cycle is most pronounced at higher altitudes, above $30 \mathrm{~km}$ (not shown). In particular in the Southern Hemisphere, the QBO terms play a larger role, and QBO variations can clearly be identified there (Fig. 6, first row, middle and right panel). Near the tropical tropopause (Fig. 6, second row, left panel), the mean age varies between about 0.2 and $1.2 \mathrm{yr}$, with lowest age in the hemispheric winter/spring, one larger value at $1.8 \mathrm{yr}$, and a slight linear decrease over the $8 \mathrm{yr}$ period. At the same time, we find similar ages of 0 to $1.2 \mathrm{yr}$ for $10^{\circ} \mathrm{N}-20^{\circ} \mathrm{N}$, with lowest ages shifted by 6 months in phase, again in the hemispheric winter/spring, and a slight increase (not shown). The hemispheric differences reflect the well-known fact that upwelling in the tropical branch of the Brewer-Dobson circulation is strongest during hemispheric winter, while during hemispheric summer, the Brewer-Dobson circulation becomes rather weak. As shown in Fig. 3 the zero isoline of AoA is in between 12 and $15 \mathrm{~km}$, in agreement with our reference at the top of the well-mixed tropical free troposphere between 9 and $15 \mathrm{~km}$ (which agrees well with the groundbased in-situ data as demonstrated in Fig. 2). The variation of AoA at fixed altitudes near the tropical tropopause is probably caused by the variation of the tropopause altitude over latitude and time itself. Further, lateral in-mixing of non-tropical air must be considered even for the TTL and the lowermost tropical stratosphere. As suggested later, increased mixing due to weakening of mixing barriers over the $8 \mathrm{yr}$ period would result in in-mixing of older midlatitudinal air and increase the AoA even in the tropical lower stratosphere, just by changing the shape of the age spectrum. The process of in-mixing itself is probably time dependent which explains variation of AoA also in the vicinity of the tropical tropopause. The sine and cosine contributions with other period lengths have generally low amplitudes and do contribute to the fit mainly by correcting the shape of the dominating oscillations.

Most interesting, however, is the linear increase/decrease which is present in all altitude/latitude bins and varies considerably. In the examples shown here, the linear increase is positive for the Northern mid-latitudes at all altitudes (Fig. 6, third row), and the inner tropics (Fig. 6, second row) and Southern subtropics in the middle stratosphere $(25 \mathrm{~km})$ (Fig. 6, first row), while it is negative for the middle and upper stratosphere of the Northern polar region (Fig. 6, fourth row, right panel), and in the inner tropics and Southern subtropics for the lower stratosphere (Fig. 6, first and second row, left and middle panels), as well as for the upper stratosphere (not shown). The full global picture will be discussed in Sect. 6. Before this, the potential impact of subsidence of $\mathrm{SF}_{6}$-depleted mesospheric air in winter polar vortices on the linear increase/decrease for all latitudes will be assessed.

\subsection{Impact of $\mathrm{SF}_{6}$-depleted, downward-transported mesospheric air masses on the age of air distribution}

Mesospheric air is depleted in $\mathrm{SF}_{6}$ due to a chemical loss reaction including electron capture and subsequent break-up of the molecule (Hall and Waugh, 1998; Reddmann et al., 2001; Stiller et al., 2008). The $\mathrm{SF}_{6}$ depletion of mesospheric air can be mistaken as indication of very high age. In particular, if $\mathrm{SF}_{6}$-depleted air subsides into the stratosphere in the polar winter vortices, air might be dated very old due to its low $\mathrm{SF}_{6}$ content (Engel et al., 2006; Stiller et al., 2008). The term "apparent age" has been chosen (Waugh and Hall, 2002) to describe age of air which seems to be older than in reality due to in-mixed $\mathrm{SF}_{6}$-depleted mesospheric air. However, in-mixing of subsided $\mathrm{SF}_{6}$-depleted mesospheric air into the air masses of lower latitudes after the break-down of the polar vortices has the potential to "over-age" also lower latitude air if age is determined from $\mathrm{SF}_{6}$. These intrusions of mesospheric air imply an uncertainty when the Brewer-Dobson circulation is diagnosed by means of the mean apparent age derived from the measured $\mathrm{SF}_{6}$ amount.

Besides the direct effect on measured apparent versus real age, the mesospheric sink may also have an impact on AoA trends. The mesospheric sink of $\mathrm{SF}_{6}$ due to electron-capture and subsequent break-up of the molecule is, as every firstorder chemical loss process, proportional to the abundance 
of the reactant $\mathrm{SF}_{6}$ (and also to that of the available electrons). Since $\mathrm{SF}_{6}$ has been increasing strongly over the last decades, it should be expected that $\mathrm{SF}_{6}$ loss in the mesosphere also has been increasing over the last years in absolute terms. This would result in an increasing difference between apparent and real age of air, and it could produce an artificial positive trend in stratospheric age of air, if in-mixing of depleted mesospheric air into hemispheric stratospheric air happens to a noticeable amount. In the following this source of uncertainty is assessed in more detail.

In each polar winter mesospheric air intrudes into the stratospheric polar vortex. During final warming events Southern polar vortices are vertically divided at typically $35 \mathrm{~km}$ altitude in an upper and a lower part by mid-latitudinal air penetrating into polar regions (see Fig. 7 and movie in the Supplement). The upper part of the vortex remnant ascends back into the mesosphere while its mixing barriers discernable as regions of still strong AoA gradients - remain intact. The lower vortex remnant is mixed with midlatitudinal air, thus contains air irreversibly subsided from the mesosphere into the stratosphere, affecting the mean age such that through diluted polar ex-mesospheric air the apparent age becomes higher than the true one. Similar behaviour is observed for Northern polar vortices, except that the subsidence of mesospheric air is less pronounced and that the vertical splitting of the vortex is typically not visible in latitudinal means (which certainly does not exclude that it may be present in longitudinally resolved representation). The entire vortex air seems to be mixed into the mid-latitudes. The effect of too large apparent air is also to be considered here.

In the following we quantify the over-aging of non-tropical (polar and mid-latitudinal) air by mesospheric contamination from estimates of the mean excess age of polar vortex air and the amount of ex-mesospheric air mixed with hemispheric non-tropical air after the final warming for several Northern and Southern winters (Table 1). The volume of the polar vortex was estimated from the positions of the highest vertical and horizontal gradients in the zonal mean age of air distribution. Similarly, the position of the subtropical mixing barrier was estimated from the position of high horizontal gradients in AoA to determine the volume of non-tropical stratospheric air. Excess age ranges from $0.03 \mathrm{yr}$ for northern hemispheric winter 2002/2003 to $0.21 \mathrm{yr}$ for southern hemispheric winter 2009. No clear trend in excess age could be determined. Obviously, the amount of air subsided from the mesosphere varies strongly, since it depends on the volume of the polar vortices, and the altitude down to which mesospheric air subsides, which both seem to be very variable from year to year.

A second aspect is that over-aging obviously accumulates over the years since after each winter, $\mathrm{SF}_{6}$-depleted air is mixed again into the stratospheric air at lower latitudes. The effect of accumulative over-aging over the years could not be quantified in detail because we have not sufficient knowledge on the detailed nature of net fluxes from the stratosphere into the troposphere. However, if we assume the mean age
Table 1. "Over-aging" of non-tropical air due to in-mixing of mesospheric, $\mathrm{SF}_{6}$-depleted air.

\begin{tabular}{lccc}
\hline Event & $\begin{array}{c}\Delta \text { age of } \\
\text { vortex air }(\mathrm{yr})\end{array}$ & $\begin{array}{c}\text { Amount of vortex } \\
\text { air (mole) }\end{array}$ & $\begin{array}{c}\text { "Over-aging" of } \\
\text { non-tropical air }(\mathrm{yr})\end{array}$ \\
\hline SH2002 & 0.50 & $0.23 \times 10^{17}$ & 0.008 \\
NH2003 & 0.50 & $0.14 \times 10^{17}$ & 0.003 \\
SH2003 & 1.00 & $0.94 \times 10^{17}$ & 0.071 \\
NH2006 & 1.00 & $0.15 \times 10^{18}$ & 0.142 \\
SH2006 & 1.50 & $0.15 \times 10^{18}$ & 0.188 \\
NH2007 & 1.00 & $0.92 \times 10^{17}$ & 0.046 \\
SH2007 & 3.00 & $0.12 \times 10^{18}$ & 0.183 \\
NH2008 & 1.00 & $0.51 \times 10^{17}$ & 0.032 \\
SH2008 & 2.00 & $0.86 \times 10^{17}$ & 0.083 \\
NH2009 & 2.00 & $0.12 \times 10^{18}$ & 0.190 \\
SH2009 & 4.00 & $0.10 \times 10^{18}$ & 0.207 \\
\hline
\end{tabular}

of stratospheric air to be on average $5 \mathrm{yr}$, this suggests that 5 contamination events per hemisphere have to be considered. With the numbers of Table 1, we assessed the overaging of Southern Hemisphere non-tropical air after 5 contaminations at $0.8 \mathrm{yr}$, and the Northern Hemisphere nontropical air at $0.4 \mathrm{yr}$. Extending the in-mixing to the equator (i.e. doubling of air volume) gives an average over-aging per contamination event of $0.08 \mathrm{yr}$ for the Southern Hemisphere and $0.04 \mathrm{yr}$ for the Northern Hemisphere.

Thus, we have corrected monthly mean southern hemispheric (northern hemispheric) AoA data by an amount of $-0.08(-0.04) \mathrm{yr}$ per year of age to account for the accumulative over-aging the air parcel has experienced in its stratospheric "lifetime". We performed the same analysis of the corrected AoA data set as described in Sect. 4.1 and obtained similar results. As an example, Fig. 8 compares the time series of AoA for 30 to $40^{\circ} \mathrm{N}, 24 \mathrm{~km}$ which has been corrected for average over-aging (top) with the original one (bottom). The absolute AoA values have been reduced by about $0.2 \mathrm{yr}$. The linear increase, however, remained unchanged within its uncertainties (for this example, $0.59 \mathrm{yr} \mathrm{decade}^{-1}$ for the corrected time series versus $0.61 \mathrm{yr} \mathrm{decade}^{-1}$ for the uncorrected time series). We conclude therefore, that in-mixing of mesospheric $\mathrm{SF}_{6}$-depleted air plays a minor role for the assessment of AoA trends, at least within the framework of our approach.

\section{Amplitudes and phases of the seasonal variation}

Figure 9 presents the amplitudes and phases of the seasonal variation of age of air, as derived by the regression method outline in Sect. 4. We used the uncorrected original data here in order to avoid to introduce any bias or artefacts in the data since our estimate for over-aging correction is still rather rough. The phases of the seasonal variation has been determined from the amplitudes of sine and cosine terms with period length 1 yr. The middle and bottom panel of Fig. 9 


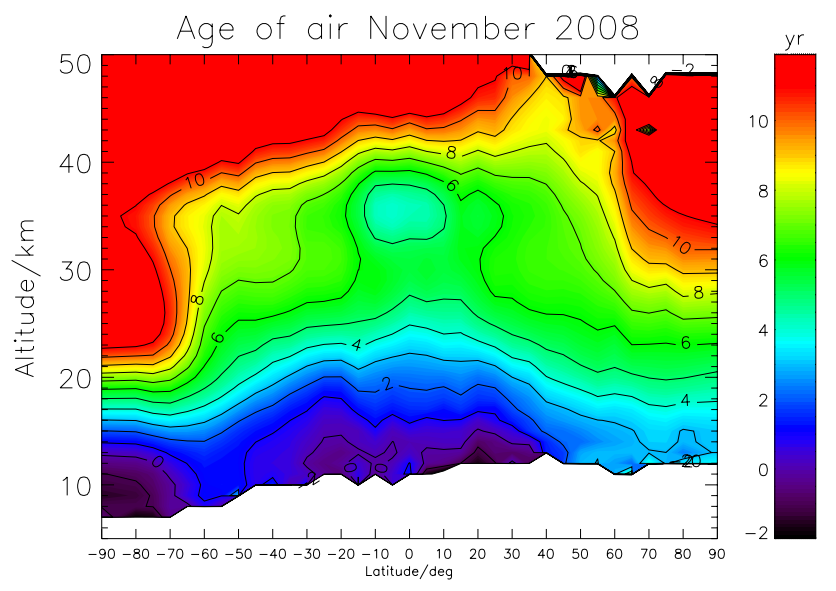

Fig. 7. Zonal mean distribution of mean age of air of November 2008 showing the beginning break-down of the polar vortex and the intrusion of relatively young air to polar latitudes around $35 \mathrm{~km}$.

provide the months of minimum and maximum AoA, respectively, during the seasonal cycle.

The amplitudes of the seasonal variation of AoA are strongest in the polar regions. This is to be expected due to the intrusion of old and possibly $\mathrm{SF}_{6}$-depleted mesospheric air into the stratosphere during winter. Poleward of $60^{\circ}$ and above approx. $25 \mathrm{~km}$, the phase shifts indicate that oldest air is observed in hemispheric spring to summer in the Southern Hemisphere, and hemispheric late winter to spring in the Northern Hemisphere. At altitudes below approx. $25 \mathrm{~km}$, air is oldest in northern hemispheric spring and early summer for the Northern Hemisphere, and youngest in hemispheric winter, so that a phase shift of almost half a year appears at Northern polar latitudes between 20 and $30 \mathrm{~km}$. This indicates that air below approx. $25 \mathrm{~km}$ in the vortex is quite well isolated from subsiding mesospheric air, i.e. subsidence usually does not reach such far down.

While seasonal amplitudes of AoA are large over wide parts of the Southern mid-latitudes, there is a region in the Northern Hemisphere with very small and almost zero seasonal variation. This indicates that the southern hemispheric mid-latitudes above approx. $25 \mathrm{~km}$ are well coupled to the polar vortex, and significant in-mixing of vortex air with a strong seasonal cycle takes place. Close to the polar vortex, the southern hemispheric mid-latitudes are more or less in phase with the vortex air, while at lower latitudes (at $50^{\circ} \mathrm{S}-$ $30^{\circ} \mathrm{S}, 20-30 \mathrm{~km}$ ), oldest air is observed in hemispheric summer to fall.

In the Northern mid-latitude middle stratosphere, the seasonality of age of air is coupled to the tropics, and youngest air (oldest air) occurs in winter (summer), i.e. a phase shift of almost half a year with respect to the polar region is present, similar to the Southern Hemisphere.

Both the Northern and the Southern tropics show a very small seasonality with amplitudes close to zero, and the
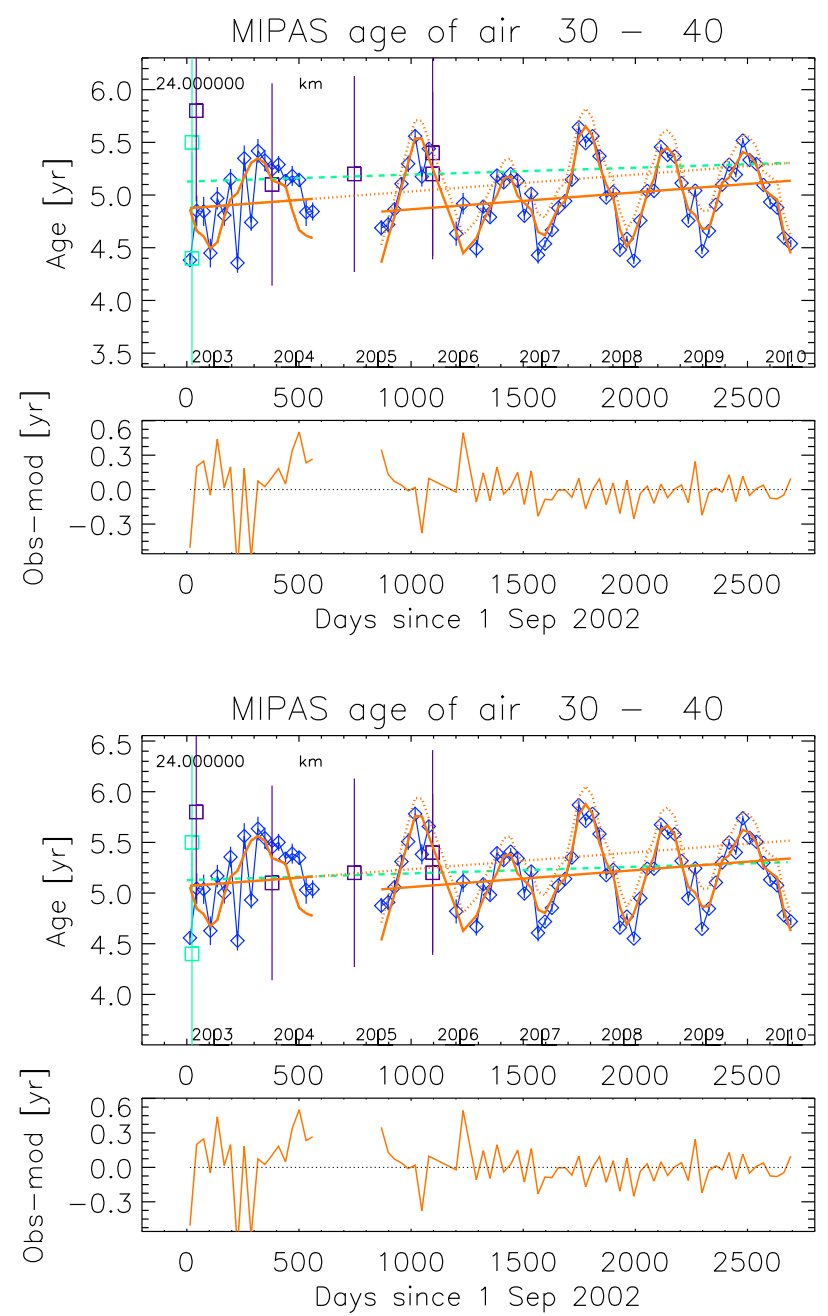

Fig. 8. Temporal evolution of mean age of air for $30^{\circ} \mathrm{N}$ to $40^{\circ} \mathrm{N}$, $24 \mathrm{~km}$ with correction of "over-aging" (top) and without (bottom). The linear increase in the top panel is $0.59 \mathrm{yrdecade}^{-1}$, compared to $0.61 \mathrm{yr}$ decade $^{-1}$ without "over-aging"-correction. The green dashed line is the 30-yr trend derived by Engel et al. (2009), and the green and violet squares are the data points and their uncertainties of the Engel et al. (2009) study which fall into the observation period of MIPAS.

phase indicates youngest air in boreal winter. This is expected for the Northern hemispheric Brewer-Dobson circulation which exhibits strongest upwelling in boreal winter, however it is interesting to see that the Southern tropics are in phase with the Northern tropics. The only exception in the Southern tropics is the region between 0 and $20^{\circ} \mathrm{S}$ below $21 \mathrm{~km}$ where youngest air is observed in the austral, not boreal winter.

An interesting region is the band of high seasonal amplitudes in the Northern Hemisphere which starts around 20 $30^{\circ} \mathrm{N}, 17 \mathrm{~km}$ and stretches to $50-60^{\circ} \mathrm{N}, 40 \mathrm{~km}$. This region is roughly in phase with the tropics and the remaining Northern mid-latitudes, and is surrounded of regions with 

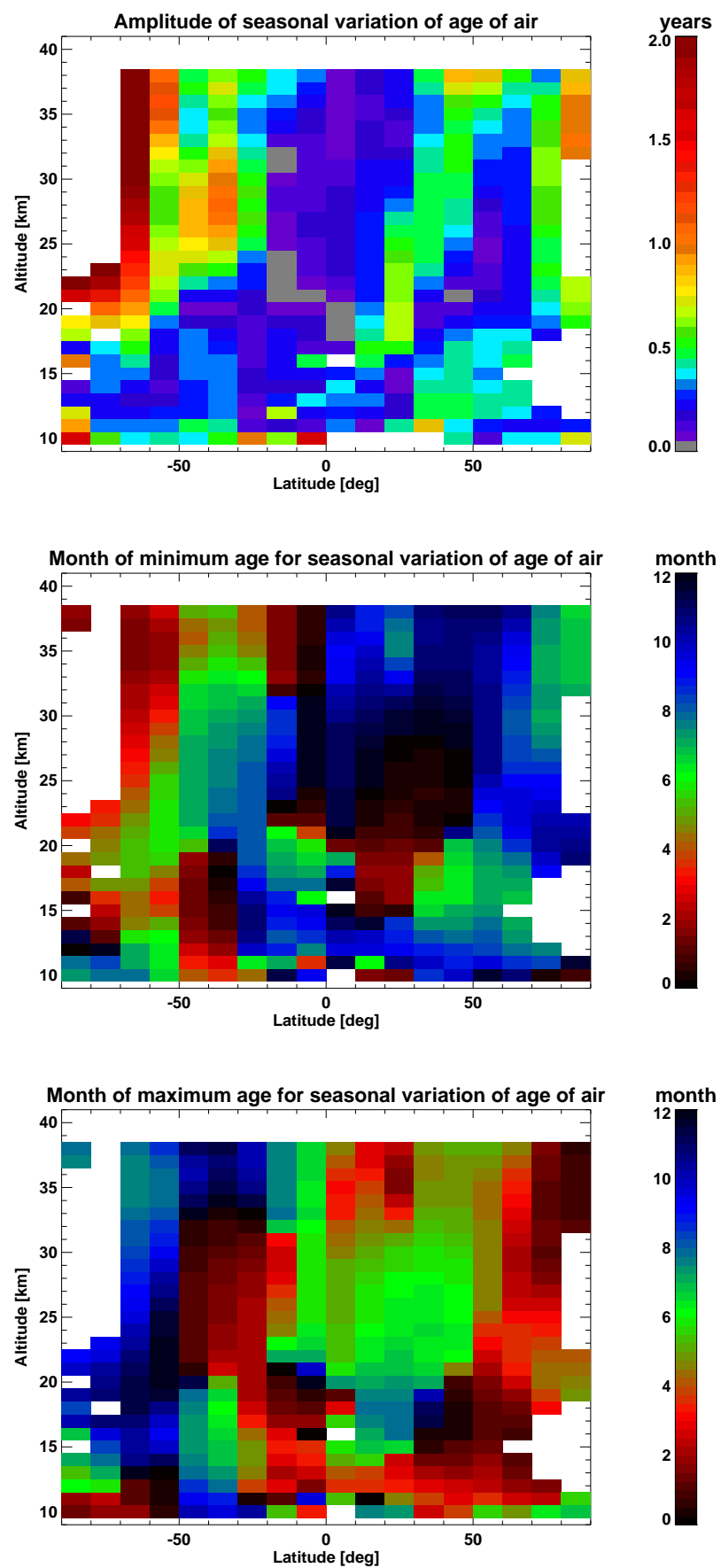

Fig. 9. Altitude-latitude cross-sections of amplitudes (top) and month of the minimum (middle) and maximum (bottom) of the seasonal variation of mean age of air.

low seasonal amplitudes, so that in-mixing of air with high seasonality, as it is the case at the vortex boundary, cannot explain the high amplitudes. We speculate that a seasonality in the position and/or the strength of the sub-tropical mixing barrier produces the strong seasonal variation in this region, so that the air sampled in this region is of tropical origin in winter when it is youngest, and of mid-latitudinal origin in summer when it is oldest (compare also Fig. 5).

The mid-latitude lowermost stratospheres in both hemispheres are other interesting regions. In the Northern Hemisphere, the seasonal amplitudes are high, and the phase is shifted by half a year with respect to its surroundings, i.e. youngest air is found in summer and fall. We interprete this as indication that the shallow branch of the Brewer-Dobson circulation which transports air within the so-called "tropically controlled transition region" (Rosenlof et al., 1997; Birner and Bönisch, 2011; Bönisch et al., 2011) dominates here. The subtropical jet is weakest and most permeable in summer, allowing intrusion of young tropical air into the mid-latitudinal lowermost stratosphere in summer. The seasonality in the mid-latitudinal lowermost stratosphere thus is caused by the variation of the permeability of the subtropical jet with season.

Although we see a similar phase shift of half a year towards southern hemispheric summer for the mid-latitudinal lowermost stratosphere in the Southern Hemisphere, the seasonal amplitudes remain small there. This can either mean that the exchange through the Southern subtropical jet is less effective, or that the contrast of age of air between the Southern tropics and the Southern mid-latitudes is smaller than in the Northern Hemisphere.

\section{Altitude- and latitude dependence of the linear increase/decrease}

We understand the linear increase/decrease (in the following: linear increase) derived from our regression analysis as the joint effect of all atmospheric variability which can be expressed by a linear regression function and which cannot be characterised by the QBO term or the periodics under consideration. It is strictly valid for the observation period of 2002 to 2010 only, thus we hesitate to call it "trend". Instead, we would like to point out that this linear increase can be affected by non-periodic atmospheric variation or clustered events. Consideration of uncertainties introduced by the latter effects will be discussed in Sect. 7.

As already obvious from Fig. 6, the linear increase of AoA is by far not homogeneous over altitudes and latitudes, but reveals a significant variation. The global view is presented in Fig. 10, top panel. Red areas indicate increasing AoA, while blue regions indicate decreasing AoA. A large contiguous region of increasing AoA is seen in the non-polar Northern stratosphere over all altitudes and the mid-stratosphere (22 to $32 \mathrm{~km}$ ) tropics and Southern mid-latitudes. Further, the Southern polar region at high altitudes also reveals an increasing AoA. In contrast, the lowermost and upper tropical stratosphere, the Northern polar regions, and some parts of Southern higher latitudes show decreasing age of air for the 2002 to 2010 period. The uncertainties are rather small (see Fig. 10, middle panel) and the results are significant on the 

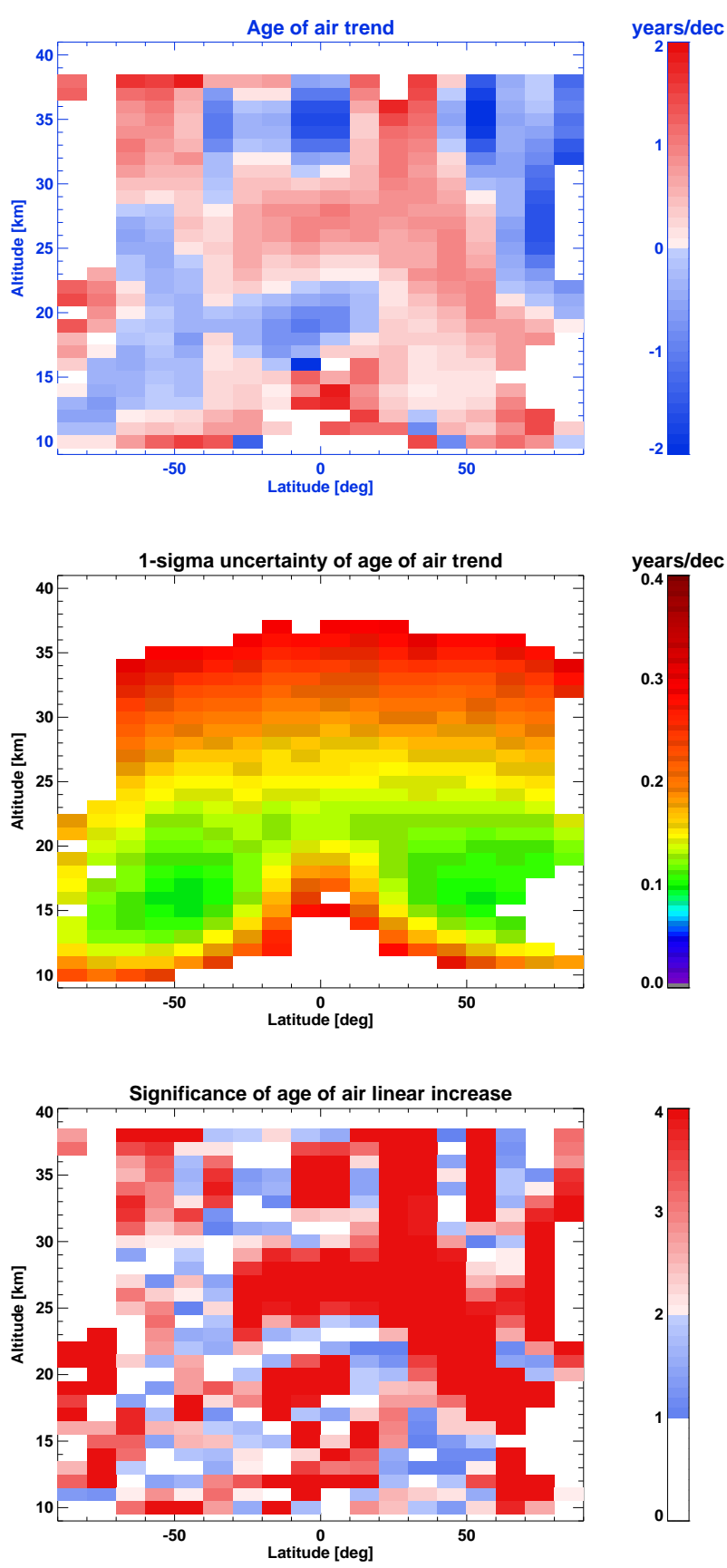

Fig. 10. Altitude-latitude cross-sections of the age of air linear increase/decrease over the years 2002 to 2010 (top), together with its $1-\sigma$ uncertainties (middle) and significance in terms of multiples of $\sigma$ (bottom).

2- $\sigma$ or better level for many of the altitude/latitude bins (see Fig. 10, bottom panel). The vertical profiles of AoA linear variation for every second latitude bin are shown in Fig. 11, together with their $2-\sigma$ uncertainties.

Engel et al. (2009) derived a trend of AoA for 30 to $50^{\circ} \mathrm{N}$ of $+0.24 \pm 0.22 \mathrm{yr}$ per decade (1- $\sigma$ uncertainty level) for the

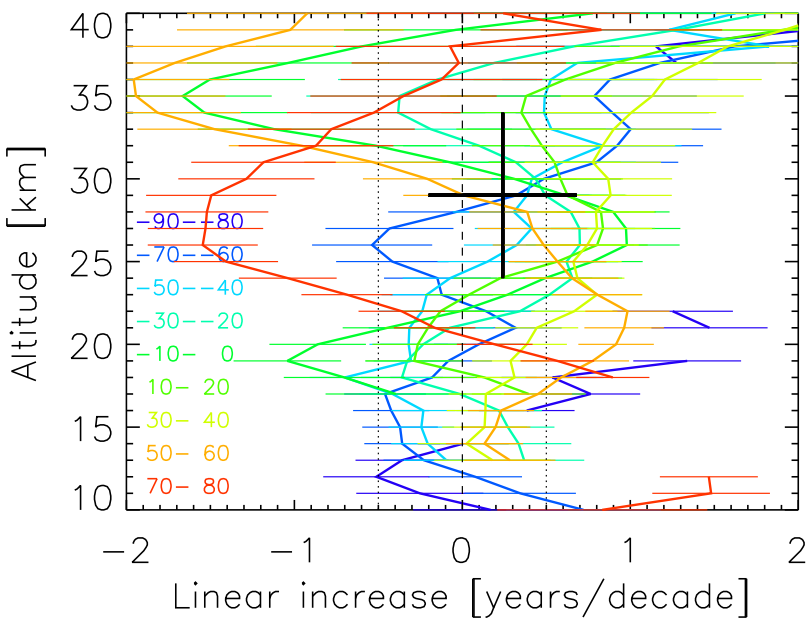

Fig. 11. Vertical profiles of the age of air linear increase/decrease over the years 2002 to 2010 for example latitudes. Horizontal bars give the 2- $\sigma$ uncertainties of the linear variations. The $30-\mathrm{yr}$ trend as derived by Engel et al. (2009) is also shown for comparison as a black cross indicating its valid altitude range and its $2-\sigma$ uncertainty.

24 to $35 \mathrm{~km}$ altitude range. For the Northern mid-latitudes in the 24 to $35 \mathrm{~km}$ altitude region, the linear increase derived from MIPAS data is significantly larger on the $1-\sigma$ level (see Fig. 11), and just consistent on the $2-\sigma$ level, to that derived by Engel et al. (2009) (compare also Fig. 8). For Northern mid-latitudes, the AoA increase derived from MIPAS is significantly distinct from zero for all altitudes above $17 \mathrm{~km}$. The observed increase of Northern mid-latitudinal AoA as presented first by Engel et al. (2009) is thus confirmed by our observations, the steepness of the increase, however, is even larger in our data set than in the 30-yr data record of Engel et al. (2009). It should be kept in mind that the two data sets represent two time periods with only little overlap: the Engel et al. (2009) data set covers the years 1975 to 2005, while MIPAS covers the years 2002 to 2010. As mentioned earlier, non-periodic atmospheric variability or clustered short-time events like frequent sudden stratospheric warmings, ENSO events or volcanic eruptions in the respective periods have the potential to affect the steepness of the linear increase.

Although Engel et al. (2009) did not discuss any indication of the impact of solar cycle variability, we must also keep in mind that the MIPAS time series covers the declining phase of solar cycle 23 and the deep minimum after 2008 only. Due to this coincidence, any solar signal in the global circulation which may occur, according to e.g. Kodera and Kuroda (2002) or Labitzke (1987), could not be separated from the longer-term variation and thus may be hidden in the linear increase.

The pattern of observed increases and decreases of AoA is rather unexpected. The increase in the Southern polar region could come from the potential artifact discussed earlier: mesospheric $\mathrm{SF}_{6}$-depleted air is expected to be the 
more depleted the higher the $\mathrm{SF}_{6}$ abundance is, and this results in a positive artificial AoA trend when dating air by its $\mathrm{SF}_{6}$ abundance (see Sect. 4.2). For the tropics, we find decreasing AoA for the lowermost and the upper stratosphere while in the middle stratosphere, AoA is becoming older. This cannot be explained by increasing uplift velocities in the lowermost and upper stratosphere and decreasing uplift velocities (or even descending air) in the middle stratosphere. Instead we suggest to take the age spectrum into account: mean AoA is not only changed by changing transit times but by changes in the shape of the age spectrum, i.e. by variation of mixing over the observation period. The increase of AoA in the middle tropical stratosphere could be explained as effect of increased in-mixing of older air from higher latitudes, thus changing the age spectrum to a shape with a longer tail, without affecting directly its youngest part which is ruled by vertical advection. The parts of the Southern Hemisphere showing decreasing AoA might be directly affected by a stronger circulation following the stronger uplift as seen in the lowermost tropical stratosphere. In contrast to this, the Northern midlatitudinal air became older over the observation period while the Northern polar air became younger. Both these observations could be the result of intensified mixing of polar and midlatitudinal air due to frequent major mid-winter warmings during the last years (see http://www.geo.fu-berlin.de/met/ $\mathrm{ag} / \mathrm{strat} /$ produkte/northpole/index.html). At least the years 2002/2003, 2003/2004, 2005/2006 and 2008/2009 revealed major sudden stratospheric warmings in mid-winter which led to a complete destruction of the stratospheric vortex implying almost complete mixing of mid-latitudinal and polar air. These severe mixing events potentially increased the age of mid-latitudinal and decreased the age of polar air.

The MIPAS-derived AoA increase is highly inconsistent to model results. The results of model calculations published so far indicate consistently a decrease in age of air over past decades and predict further decrease for future decades (Waugh, 2009; Austin and Li, 2006; Garcia et al., 2011; SPARC CCMVal, 2010). E.g. Waugh (2009) presented a compilation of model results for Northern mid-latitudes covering the years 1960 to 2005; they showed consistently an acceleration of the Brewer-Dobson circulation expressed as a decrease of age of air from -0.05 to $-0.20 \mathrm{yrdecade}^{-1}$, which is in sharp contrast to the observed increase presented in this study.

Recent model results (Garcia et al., 2011) present the variation of age of air for the mid-latitude stratosphere $\left(40.7^{\circ} \mathrm{N}, 20 \mathrm{hPa}\right)$ and the tropical middle stratosphere $\left(0.9^{\circ} \mathrm{N}, 10.7 \mathrm{hPa}\right)$ and obtain for both locations statistically significant over-all decreases of AoA. The time series, however, show considerable variation in the steepness of the decrease, and even shorter-term periods (of approx. $5 \mathrm{yr}$ ) for which AoA increases. For the period 2000 to 2006, however, the trend is negative in all presentations of model results in this paper.
Randel et al. (2006) concluded from observations of water vapor and temperature in the tropical lower stratosphere after 2001, that the upwelling across the tropical tropopause should have increased, and linked this observation to an intensification of the Brewer-Dobson circulation. Randel and Thompson (2011) confirmed these findings on basis of tropical ozone observations, and extended the relevant period to 1984 to 2009. These observations are consistent to the findings from our data analysis, since indeed we derive decreasing age of air in the lowermost stratosphere below $22 \mathrm{~km}$ from $30^{\circ} \mathrm{S}$ to $20^{\circ} \mathrm{N}$. Decreasing AoA was also found in the upper part of the tropical pipe above $32 \mathrm{~km}$, but not in the intermediate region of 22 to $32 \mathrm{~km}$.

Several attempts have been made to resolve the contradiction between the Engel et al. (2009) observations and the model results. Ray et al. (2010) introduced the socalled "Leaky tropical pipe model" including a term that allows mixing of air from the mid-latitudes into the tropics to be consistent with observations of the tropical stratosphere. They found that the best quantitative agreement with observed mean age and ozone trends was achieved assuming a small strengthening of the mean circulation in the lower stratosphere, a moderate weakening of the mean circulation in the middle and upper stratosphere, and a moderate increase in the horizontal mixing into the tropics. They also found that the mean age of air trends are strongly sensitive to trends in the horizontal mixing into the tropics.

Applied to our observations, strengthening of the mean circulation together with weakening of mixing barriers would be a plausible hypothesis to explain the pattern of increasing and decreasing AoA over altitudes/latitudes as shown in Fig. 10, top panel. Weakening of the mixing barrier along the Northern polar vortex (by e.g. frequent major midwinter warmings) would cause polar air becoming younger, and mid-latitudinal air becoming older. Weakening of the subtropic mixing barrier in the middle stratosphere would cause middle stratospheric tropical air becoming older by changing the shape of the age spectrum, while increased upwelling due to intensified Brewer-Dobson circulation would result in younger air in the lowermost and uppermost tropical stratosphere, regions which were not affected by changes in the strength of the subtropical mixing barrier. Changes in the strength of the mixing barriers then would obviously be less pronounced in the Southern Hemisphere, since areas with decreasing age of air - consistent to an intensification of the Brewer-Dobson circulation - are found in the Southern mid-latitudes. The Southern polar vortex air is becoming older as expected from in-mixing of increasingly stronger $\mathrm{SF}_{6}$-depleted air as outlined in Sect. 4.2. Within this scenario, longer-term weakening of the mixing barriers formed by the subtropical jets seems not to be confirmed, since mid-latitudinal air in the lowermost stratosphere is becoming older, i.e. a direct coupling to the air with decreasing age in the lowermost tropical stratosphere is not very probable. This result is in contradiction to findings of Birner and 
Bönisch (2011) and Bönisch et al. (2011) who deduced an intensification of the shallow branch of the Brewer-Dobson circulation from observations and transit-time calculations.

\section{Impact of empirical errors and autocorrelation}

As already said, linear increases/decreases analysed so far are understood as the joint effect of all atmospheric variability which can be expressed by our regression model which includes the linear trend, several periodics and the QBO term. This simplified model, however, cannot include non-periodic events like sudden stratospheric warmings, El Niño southern oscillation warm events and other atmospheric perturbations. These phenomena lead to residuals in the trend fit which are not accounted for by the error estimates of the monthly mean age data which include only the standard errors of the monthly averages and the correlated term to account for the possible bias between the MIPAS data subsets. This leads for most cases to a $\chi_{\text {reduced }}^{2}$ of the fit

$\chi_{\text {reduced }}^{2}=$

$\frac{\left(\boldsymbol{a} \boldsymbol{g} \boldsymbol{e}_{\mathrm{MIPAS}}-\boldsymbol{a g} \boldsymbol{e}_{\text {modeled }}\right)^{T} \mathbf{S}_{\mathrm{m}}^{-1}\left(\boldsymbol{a} \boldsymbol{g} \boldsymbol{e}_{\mathrm{MIPAS}}-\boldsymbol{a g} \boldsymbol{e}_{\text {modeled }}\right)}{m-n}$

considerably larger than unity, where $\boldsymbol{a g} \boldsymbol{e}_{\text {MIPAS }}$ and $\boldsymbol{a g} \boldsymbol{e}_{\text {modeled }}$ are the data vectors containing the measured and modeled age values, respectively, and where $m$ and $n$ are the number of data pairs and the number of fitted coefficients, respectively. In other words, the fit residuals are systematically larger than the error bars of the data. This hints at atmospheric variability not covered by our simple parametric trend model. While the linear increases/decreases discussed so far are the appropriate quantity for comparison to those determined in a similar manner from a model run representing the non-periodic perturbations correctly, these perturbations affect the estimation of the true atmospheric trend and its uncertainty. Thus, we add a constant model uncertainty error term to the data error covariance matrix $\mathbf{S}_{\mathrm{m}}$. Since we cannot exclude that these perturbations to be accounted for by this additional error term have a typical duration of more than one month, covariance terms between adjacent datapoints were also considered in order to account for the resulting autocorrelation. This constant model uncertainty error term added to the covariance matrix represents the deficiencies of the regression model with respect to the true atmospheric variation and was, within an iterative procedure, scaled such that the resulting $\chi_{\text {reduced }}^{2}$ of the trend fit was close to unity, corresponding to combined data and model uncertainties consistent to the fit residuals.

Contrary to the purely observation-error based linear increase/decrease as presented in the previous section, which represents the linear approximation of the superposition of multiple atmospheric variations leading to any kind of longterm change, we call the change of age with time derived
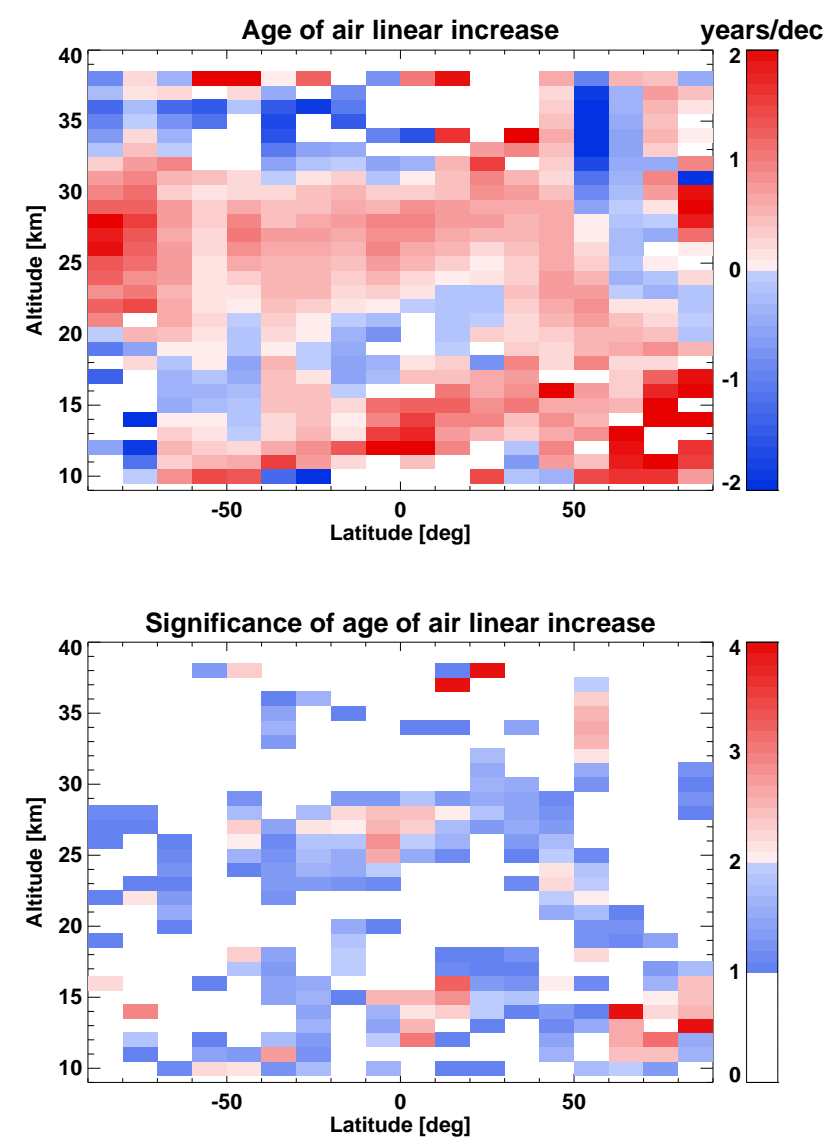

Fig. 12. Altitude-latitude cross-section of the AoA model-error corrected linear increase (top) and its significance in terms of multiples of $\sigma$ (bottom) after including the model error and autocorrelations between the data points in the fit.

under consideration of all non-linear and unaccounted atmospheric variation as regression model error "model-error corrected linear increase (MECLI)" (see Fig. 12, upper panel). The individual results for each altitude/latitude bin change only marginally compared to the linear increase shown in Fig. 10, and the overall patterns remain similar, at least below $30 \mathrm{~km}$. As expected, this additional consideration of the trend model uncertainties leads to larger uncertainties of the linear increase (MECLI), and results are thus less significant than those obtained by accounting for data errors only (Fig. 12, lower panel). Nevertheless, the patterns of increasing and decreasing ages are contiguous rather than patchy, indicating that analysis at reduced latitudinal or altitudinal resolution would improve the significance, and that the linear increases (MECLI) might be more reliable than the single-bin error bars suggest. 


\section{Conclusions}

More than $10^{6} \mathrm{SF}_{6}$ profiles were retrieved from MIPAS limb emission mid-infrared spectral data (ESA version 4.61 up to 4.67) over the observation period of 2002 to January 2010. The retrieval procedure followed in general Stiller et al. (2008), and only few adjustments were made to account for the reduced spectral resolution of MIPAS data after 2005 . Mean age of stratospheric air was derived from the $\mathrm{SF}_{6}$ data by referencing any stratospheric $\mathrm{SF}_{6}$ observation to the time the same $\mathrm{SF}_{6}$ amount had been observed in the well-mixed free upper tropical troposphere below the tropical transition layer, represented by a global mean derived from a global network of NOAA/ESRL insitu and flask observations (Hall et al., 2011). Since the tropospheric $\mathrm{SF}_{6}$ did not increase strictly linearly over the last years, a non-linearity correction was applied in the age of air derivation which iteratively searched for that age of air which is consistent to the observed $\mathrm{SF}_{6}$ after convolution with the age spectrum. The applied corrections, however, where in general smaller than $0.2 \mathrm{yr}$. The derived age of air data agree within $0.3 \mathrm{yr}$ with age of air data as published by Engel et al. (2009). The latitudinal cross-sections of age of air at $20 \mathrm{~km}$ altitude derived from airborne observations in the 1990s as published by Waugh and Hall (2002) are consistent to our data in the sense that they almost all fall into the range of values covered by MIPAS monthly averages of age of air.

Time series of monthly zonal means of age of air on $10^{\circ}$ latitude bins and $1-2 \mathrm{~km}$ altitude bins were analysed with a regression function including a constant and a linear term, two QBO proxy terms, and 8 sine and cosine terms, the first two of which represent the seasonal and the semi-annual variations. The global distributions of linear increases/decreases, and seasonal amplitudes and phases reveal considerable variation over the globe with areas of increasing as well as decreasing age of air. Seasonal amplitudes of up to $2 \mathrm{yr}$ occur in the global age of air distribution, with highest amplitudes in the polar regions and lowest amplitudes in the tropics. The high seasonality in the polar regions comes from the intrusion of old, but possibly also $\mathrm{SF}_{6}$-depleted, mesospheric air during polar winter the latter of which causes an "over-aging" of polar air. The impact of "over-aged" (i.e. apparently older than in reality) polar air on both the age of air and its linear increase/decrease at lower latitudes was assessed and found to be small: the age of air was shifted by about $-0.2 \mathrm{yr}$, while the linear increase/decrease was affected within its uncertainties only. High seasonality in the southern hemispheric mid-latitudinal upper stratosphere indicates a considerable coupling of these air masses to the polar region, i.e. in-mixing of old polar air after the break-down of the polar vortex occurs regularly. Other regions of high seasonality are a band in the Northern mid-latitudes which might obtain its seasonality from the subtropical mixing barrier shifting its position or varying its strength within a seasonal cycle, and the lowermost stratosphere in the Northern mid-latitudes, which obtains its seasonality from the permeability of the subtropical jet with highest permeability (and youngest air in mid-latitudes) in late summer. The analysis of the phases of the seasonal variation indicates, that most of the Northern mid-latitudes follow the tropics in their phase, i.e. have youngest air in (late) winter, in accordance with the more intensive Brewer-Dobson circulation in the winter hemisphere. Southern mid-latitudes are influenced from the polar regions, thus having their youngest air in Southern winter and oldest air after break-down of the polar vortex. The polar regions have their oldest air in Southern spring and Northern late winter. The linear increases/decreases are similarly inhomogeneous over the latitudes and altitudes: we find increasing age of air for the Southern polar region, most of the Northern mid-latitudes and the lower to middle tropical stratosphere, while age of air is decreasing for the lowermost and upper tropical stratosphere, some areas in the Southern mid-latitudes and the Northern polar region. Decrease of age of air in the tropical lowermost stratosphere is consistent to earlier observational evidence of increased tropical upwelling, derived from observations of tropical lower stratospheric water vapor and ozone and tropopause temperatures. The unchanged or, if any, increasing age of air as derived by Engel et al. (2009) is confirmed as well, with even steeper and statistically significant increases. The overall complicated pattern age of air increase/decrease might, as a hypothesis, be consistent with a general increasing upwelling in the tropics and intensification of the Brewer-Dobson circulation, but simultaneous weakening of the subtropical and polar mixing barriers, the latter due to frequent major midwinter warmings in the observational period. A stricter analysis of our data, taking model errors and autocorrelation within the data points into account, provides a similar picture, however with reduced significance of the mean linear increase.

In any case, the global picture of age of air and its temporal variation demonstrates that there is not one positive or negative linear variation of age of air over the globe. Future comparisons between observations and models should take these inhomogeneities into account.

The data material presented in this paper, i.e. the monthly zonal means of mean age of stratospheric air, is available as netcdf data files from the authors upon request, and a movie showing the temporal evolution of altitude-latitude crosssections of mean age of air is provided in the Supplement.

\author{
Supplementary material related to this \\ article is available online at: \\ http://www.atmos-chem-phys.net/12/3311/2012/ \\ acp-12-3311-2012-supplement.zip.
}


Acknowledgements. We would like to acknowledge provision of MIPAS level-1b data by ESA. The provision of sulfur hexaflouride data from the NOAA/ESRL halocarbons in situ program is gratefully acknowledged. We thank the PIs of the program, Bradley Hall, Geoff Dutton, and James W. Elkins II, for their support with using their data and their helpful comments on the manuscript. The work presented in this paper was funded via the "CAWSES" priority program of the German Research Foundation (DFG) within the project "Tracers and mean age". This work is also a contribution to the DFG research unit "SHARP - Stratospheric Change and its Role for Climate Prediction". Development of $\mathrm{SF}_{6}$ data retrieval was partly funded by the German Federal Ministry of Education and Research (BMBF) via contract no. 50EE0901. GPS would like to thank Greg Bodecker for helpful discussions regarding autocorrelation of data. The comments of two anonymous reviewers are gratefully appreciated.

Edited by: M. Dameris

\section{References}

Andrews, A. E., Boering, K. A., Daube, B. C., Wofsy, S. C., Hintsa, E. J., Weinstock, E. M., and Bui, T. P.: Empirical age spectra for the lower tropical stratosphere from in situ observations of $\mathrm{CO}_{2}$ : Implications for stratospheric transport, J. Geophys. Res., 104, 26581-26595, 1999.

Andrews, A. E., Boering, K. A., Daube, B. C., Wofsy, S. C., Loewenstein, M., Jost, H., Podolske, J. R., Webster, C. R., Herman, R. L., Scott, D. C., Flesch, G. J., Moyer, E. J., Elkins, J. W., Dutton, G. S., Hurst, D. F., Moore, F. L., Ray, E. A., Romashkin, P. A., and Strahan, S. E.: Mean ages of stratospheric air derived from in situ observations of $\mathrm{CO}_{2}, \mathrm{CH}_{4}$, and $\mathrm{N}_{2} \mathrm{O}$, J. Geophys. Res., 106, 32295-32314, doi:10.1029/2001JD000465, 2001.

Austin, J. and Li, F.: On the relationship between the strength of the Brewer-Dobson circulation and the age of stratospheric air, Geophys. Res. Lett., 33, L17807, doi:10.1029/2006GL026867, 2006.

Austin, J., Wilson, J., Li, F., and Vömel, H.: Evolution of water vapor and age of air in coupled chemistry climate model simulations of the stratosphere, J. Atmos. Sci., 64, 905-921, 2007.

Baldwin, M. P., Dameris, M., and Shepherd, T. G.: How will the Stratosphere affect climate change?, Science, 316, 1576-1577, doi:10.1126/science.1144303, 2007.

Birner, T. and Bönisch, H.: Residual circulation trajectories and transit times into the extratropical lowermost stratosphere, Atmos. Chem. Phys., 11, 817-827, doi:10.5194/acp-11-817-2011, 2011.

Bönisch, H., Engel, A., Birner, Th., Hoor, P., Tarasick, D. W., and Ray, E. A.: On the structural changes in the Brewer-Dobson circulation after 2000, Atmos. Chem. Phys., 11, 3937-3948, doi:10.5194/acp-11-3937-2011, 2011.

Boering, K. A., Wofsy, S. C., Daube, B. C., Schneider, H. R., Loewenstein, M., Podolske, J. R., and Conway, T. J.: Stratospheric Mean Ages and Transport Rates from Observations of Carbon Dioxide and Nitrous Oxide, Science, 274, 1340-1343, doi:10.1126/science.274.5291.1340, 1996.

Butchart, N. and Scaife, A. A.: Removal of chlorofluorocarbons by increased mass exchange between the stratosphere and troposphere in a changing climate, Nature, 410, 799-802, doi:10.1038/35071047, 2001.

Butchart, N., Scaife, A. A., Bourqui, M., de Grandpre, J., Hare, S. H. E., Kettleborough, J., Langematz, U., Manzini, E., Sassi, F., Shibata, K., Shindell, D., and Sigmond, M.: Simulations of anthropogenic change in the strength of the Brewer-Dobson circulation, Clim. Dynam., 27, 727-741, doi:10.1007/s00382-0060162-4, 2006.

Chen, B., Xu, X. D., Yang, S., and Zhao, T. L.: Climatological perspectives of air transport from atmospheric boundary layer to tropopause layer over Asian monsoon regions during boreal summer inferred from Lagrangian approach, Atmos. Chem. Phys. Discuss., 12, 4185-4219, doi:10.5194/acpd-124185-2012, 2012.

Chirkov, M., Laeng, A., von Clarmann, T., Kellmann, S., Stiller, G., Glatthor, N., Wiegele, A., and Orphal, J.: Global HCFC-22 measurements with MIPAS: retrieval, validation, climatologies and trends, to be submitted to Atmos. Chem. Phys, 2012.

Dhomse, S., Weber, M., and Burrows, J.: The relationship between tropospheric wave forcing and tropical lower stratospheric water vapor, Atmos. Chem. Phys., 8, 471-480, doi:10.5194/acp-8-4712008, 2008.

Douglass, A. R., Stolarski, R. S., Schoeberl, M. R., Jackman, C. H., Gupta, M. L., Newman, P. A., Nielsen, J. E., and Fleming, E. L.: Relationship of loss, mean age of air and the distribution of CFCs to stratospheric circulation and implications for atmospheric lifetimes, J. Geophys. Res., 113, D14309, doi:10.1029/2007JD009575, 2008.

Elkins, J. W. and Dutton, G. S.: Nitrous oxide and sulfur hexafluoride (in "State of the Climate in 2008"), B. Am. Meteorol. Soc., 90, S38-S39, 2009.

Elkins, J. W., Fahey, D. W., Gilligan, J. M., Dutton, G. S., Baring, T. J., Volk, C. M., Dunn, R. E., Myers, R. C., Montzka, S. A., Wamsley, P. R., Hayden, A. H., Butler, J. H., Thompson, T. M., Swanson, T. H., Dlugokencky, E. J., Novelli, P. C., Hurst, D. F., Lobert, J. M., Ciciora, S. J., McLaughlin, R. J., Thompson, T. L., Winkler, R. H., Fraser, P. J., Steele, L. P., and Lucarelli, M. P.: Airborne gas chromatograph for in situ measurements of longlived species in the upper troposphere and lower stratosphere, Geophys. Res. Lett., 23, 347-350, doi:10.1029/96GL00244, 1996.

Engel, A., Strunk, M., Müller, M., Haase, H.-P., Poss, C., Levin, I., and Schmidt, U.: Temporal development of total chlorine in the high-latitude stratosphere based on reference distributions of mean age derived from $\mathrm{CO}_{2}$ and $\mathrm{SF}_{6}$, J. Geophys. Res., 107, doi:10.1029/2001JD000584, 2002.

Engel, A., Möbius, T., Haase, H.-P., Bönisch, H., Wetter, T., Schmidt, U., Levin, I., Reddmann, T., Oelhaf, H., Wetzel, G., Grunow, K., Huret, N., and Pirre, M.: Observation of mesospheric air inside the arctic stratospheric polar vortex in early 2003, Atmos. Chem. Phys., 6, 267-282, doi:10.5194/acp-6-2672006, 2006.

Engel, A., Möbius, T., Bönisch, H., Schmidt, U., Heinz, R., Levin, I., Atlas, E., Aoki, S., Nakazawa, T., Sugawara, S., Moore, F., Hurst, D., Elkins, J., Schauffler, S., Andrews, A., and Boering, K.: Age of stratospheric air unchanged within uncertainties over the past $30 \mathrm{yr}$, Nat. Geosci., 2, 28-31, doi:10.1038/ngeo388, 2009.

Fischer, H., Birk, M., Blom, C., Carli, B., Carlotti, M., von Clar- 
mann, T., Delbouille, L., Dudhia, A., Ehhalt, D., Endemann, M., Flaud, J. M., Gessner, R., Kleinert, A., Koopman, R., Langen, J., López-Puertas, M., Mosner, P., Nett, H., Oelhaf, H., Perron, G., Remedios, J., Ridolfi, M., Stiller, G., and Zander, R.: MIPAS: an instrument for atmospheric and climate research, Atmos. Chem. Phys., 8, 2151-2188, doi:10.5194/acp-8-2151-2008, 2008.

Fueglistaler, S., Dessler, A., Dunkerton, T., Folkins, I., Fu, Q., and Mote, P.: Tropical tropopause layer, Rev. Geophys., 47, RG1004, doi:10.1029/2008RG000267, 2009.

Garcia, R. R. and Randel, W. J.: Acceleration of the Brewer-Dobson Circulation due to Increases in Greenhouse Gases, J. Atmos. Sci., 65, 2731-2739, doi:10.1175/2008JAS2712.1, 2008.

Garcia, R. R., Randel, W. J., and Kinnison, D. E.: On the determination of age of air trends from atmospheric trace species, J. Atmos. Sci., 68, 139-154, 2011.

Hall, B. D., Dutton, G. S., Mondeel, D. J., Nance, J. D., Rigby, M., Butler, J. H., Moore, F. L., Hurst, D. F., and Elkins, J. W.: Improving measurements of SF6 for the study of atmospheric transport and emissions, Atmos. Meas. Tech., 4, 2441-2451, doi:10.5194/amt-4-2441-2011, 2011.

Hall, T. M. and Plumb, R. A.: Age as a diagnostic of stratospheric transport, J. Geophys. Res., 99, 1059-1070, 1994.

Hall, T. M. and Waugh, D. W.: Influence of nonlocal chemistry on tracer distributions: Inferring the mean age of air from $\mathrm{SF}_{6}$, J. Geophys. Res., 103, 13327-13336, doi:10.1029/98JD00170, 1998.

Hall, T. M., Waugh, D. W., Boering, K. A., and Plumb, R. A.: Evaluation of transport in stratospheric models, J. Geophys. Res., 104, 18815-18839, 1999.

Harnisch, J., Bischof, W., Borchers, R., Fabian, P., and Maiss, M.: Tropospheric trends for $\mathrm{CF}_{4}$ and $\mathrm{C}_{2} \mathrm{H}_{6}$ since 1982 derived from $\mathrm{SF}_{6}$ dated stratospheric air, Geophys. Res. Lett., 23, 1099-1102, doi:10.1029/96GL01198, 1996.

IPCC: Contribution of Working Group I to the Fourth Assessment Report of the Intergovernmental Panel on Climate Change, in: Climate Change 2007: The Physical Science Basis, edited by: Solomon, S., Qin, D., Manning, M., Chen, Z., Marquis, M., Averyt, K. B., Tignor, M., and Miller, H. L., Cambridge University Press, Cambridge, UK and New York, NY, USA, 996 pp., 2007.

Kellmann, S., von Clarmann, T., Eckert, E., Glatthor, N., Höpfner, M., Kiefer, M., Orphal, J., Stiller, P., Funke, B., Grabowski, U., Linden, A., and Wiegele, A.: Global CFC-11 $\left(\mathrm{CFCl}_{3}\right)$ and CFC$12\left(\mathrm{CF}_{2} \mathrm{Cl}_{2}\right)$ Measurements with the Michelson Interferometer for Passive Atmospheric Sounding (MIPAS): Retrieval, Climatologies and Trends, to be submitted to Atmos. Chem. Phys, 2012.

Kodera, K. and Kuroda, Y.: Dynamical response to the solar cycle, J. Geophys. Res., 107, 4749, doi:10.1029/2002JD002224, 2002.

Kyrölä, E., Tamminen, J., Sofieva, V., Bertaux, J. L., Hauchecorne, A., Dalaudier, F., Fussen, D., Vanhellemont, F., Fanton d'Andon, O., Barrot, G., Guirlet, M., Fehr, T., and Saavedra de Miguel, L.: GOMOS $\mathrm{O}_{3}, \mathrm{NO}_{2}$, and $\mathrm{NO}_{3}$ observations in 2002-2008, Atmos. Chem. Phys., 10, 7723-7738, doi:10.5194/acp-10-77232010, 2010.

Labitzke, K.: Sunspots, the QBO, and the stratospheric temperature in the north polar region, Geophys. Res. Lett., 14, 535-537, 1987.

Levin, I., Naegler, T., Heinz, R., Osusko, D., Cuevas, E., Engel, A., Ilmberger, J., Langenfelds, R. L., Neininger, B., Rohden, C. v.,
Steele, L. P., Weller, R., Worthy, D. E., and Zimov, S. A.: The global $\mathrm{SF}_{6}$ source inferred from long-term high precision atmospheric measurements and its comparison with emission inventories, Atmos. Chem. Phys., 10, 2655-2662, doi:10.5194/acp-102655-2010, 2010.

Li, S. and Waugh, D. W.: Sensitivity of mean age and long-lived tracers to transport parameters in a two-dimensional model, J. Geophys. Res., 104, 30559-30569, doi:10.1029/1999JD900913, 1999.

McLandress, C. and Shepherd, T. G.: Simulated anthropogenic changes in the Brewer-Dobson circulation, including its extension to high latitudes, J. Climate, 22, 1516-1540, doi:10.1175/2008JCLI2679.1, 2009.

Oman, L., Waugh, D. W., Pawson, S., Stolarski, R. S., and Newman, P. A.: On the influence of anthropogenic forcings on changes in the stratospheric mean age, J. Geophys. Res., 114, D03105, doi:10.1029/2008JD010378, 2009.

Park, S., Jiménez, R., Daube, B. C., Pfister, L., Conway, T. J., Gottlieb, E. W., Chow, V. Y., Curran, D. J., Matross, D. M., Bright, A., Atlas, E. L., Bui, T. P., Gao, R.-S., Twohy, C. H., and Wofsy, S. C.: The $\mathrm{CO}_{2}$ tracer clock for the Tropical Tropopause Layer, Atmos. Chem. Phys., 7, 3989-4000, doi:10.5194/acp-7-39892007, 2007.

Patra, P., Lal, S., Subbaraya, B. H., Jackman, C. H., and Rajaratnam, P.: Observed vertical profile of sulphur hexafluoride $\left(\mathrm{SF}_{6}\right)$ and its atmospheric applications, J. Geophys. Res., 102, 8855-8859, doi:10.1029/96JD03503, 1997.

Plumb, R. A., Heres, W., Neu, J. L., Mahowald, N., del Corral, J., Toon, G. C., Ray, E., Moore, F., and Andrews, A. E.: Global tracer modeling during SOLVE: High-latitude descent and mixing, J. Geophys. Res., 107, 8309, doi:10.1029/2001JD001023, 2002.

Randel, W. J. and Thompson, A.: Interannual variability and trends in tropical ozone derived from SAGE II satellite data and SHADOZ ozonesondes, J. Geophys. Res., 116, D07303, doi:10.1029/2010JD015195, 2011.

Randel, W. J., Wu, F., Vömel, H., Nedoluha, G. E., and Forster, P.: Decreases in stratospheric water vapor after 2001: Links to changes in the tropical tropopause and the Brewer-Dobson circulation, J. Geophys. Res., 111, D12312, doi:10.1029/2005JD006744, 2006.

Ray, E. A., Moore, F. L., Elkins, J. W., Dutton, G. S., Fahey, D. W., Vömel, H., Oltmans, S. J., and Rosenlof, K. H.: Transport into the Northern Hemisphere lowermost stratosphere revealed by in situ tracer measurements, J. Geophys. Res., 104, 26565-26580, doi:10.1029/1999JD900323, 1999.

Ray, E. A., Moore, F. L., Elkins, J. W., Hurst, D. F., Romashkin, P. A., Dutton, G. S., and Fahey, D. W.: Descent and mixing in the 1999-2000 northern polar vortex inferred from in situ tracer measurements, J. Geophys. Res., 107, 8285, doi:10.1029/2001JD000961, 2002.

Ray, E. A., Moore, F. L., Rosenlof, K. H., Davis, S. M., Boenisch, H., Morgenstern, O., Smale, D., Rozanov, E., Hegglin, M., Pitari, G., Mancini, E., Braesicke, P., Butchart, N., Hardiman, S., Li, F., Shibata, K., and Plummer, D. A.: Evidence for changes in stratospheric transport and mixing overi the past three decades based on multiple data sets and tropical leaky pipe analysis, J. Geophys. Res., 115, D21304, doi:10.1029/2010JD014206, 2010. Reddmann, T., Ruhnke, R., and Kouker, W.: Three-dimensional 
model simulations of $\mathrm{SF}_{6}$ with mesospheric chemistry, J. Geophys. Res., 106, 14525-14537, doi:10.1029/2000JD900700, 2001.

Rigby, M., Mühle, J., Miller, B. R., Prinn, R. G., Krummel, P. B., Steele, L. P., Fraser, P. J., Salameh, P. K., Harth, C. M., Weiss, R. F., Greally, B. R., O’Doherty, S., Simmonds, P. G., Vollmer, M. K., Reimann, S., Kim, J., Kim, K.-R., Wang, H. J., Olivier, J. G. J., Dlugokencky, E. J., Dutton, G. S., Hall, B. D., and Elkins, J. W.: History of atmospheric $\mathrm{SF}_{6}$ from 1973 to 2008, Atmos. Chem. Phys., 10, 10305-10320, doi:10.5194/acp10-10305-2010, 2010.

Rosenlof, K. H. and Reid, G. C.: Trends in the temperature and water vapor content of the tropical lower stratosphere: Sea surface connection, J. Geophys. Res., 113, D06107, doi:10.1029/2007JD009109, 2008.

Rosenlof, K. H., Tuck, A. F., Kelly, K. K., Russell III, J. M., and McCormick, M. P.: Hemispheric asymmetries in water vapor and inferences about transport in the lower stratosphere, J. Geophys. Res., 102, 13213-13234, 1997.

Schmidt, U. and Khedim, A.: In situ measurements of carbon dioxide in the winter Arctic vortex and at midlatitudes: An indicator of the "age" of stratospheric air, Geophys. Res. Lett., 18, 763766, 1991.

Schoeberl, M. R., Douglass, A. R., Polansky, B., Boone, C., Walker, K. A., and Bernath, P.: Estimation of stratospheric age spectrum from chemical tracers, J. Geophys. Res., 110, D21303, doi:10.1029/2005JD006125, 2005.

Shepherd, T. G.: Dynamics, Stratospheric Ozone, and Climate Change, Atmosphere-Ocean, 46, 117-138, doi:10.3137/ao.460106, 2008.

Solomon, S.: Progress towards a quantitative understanding of Antarctic ozone depletion, Nature, 347, 347-354, 1990.

Solomon, S., Rosenlof, K. H., Portmann, R. W., Daniel, J. S., Davis, S. M., Sanford, T. J., and Plattner, G.-K.: Contributions of Stratospheric Water Vapor to Decadal Changes in the Rate of Global Warming, Science, 327, 1219-1223, doi:10.1126/science.1182488, 2010.

SPARC CCMVal: Neu, J. and Strahan, S., Chapter 5. Transport, in: SPARC Report on the Evaluation of ChemistryClimate Models, edited by: Eyring, V., Shepherd, T. G., and Waugh, D. W., SPARC Report No. 5, WCRP-132, WMO/TD-No. 1526, available at: http://www.sparc-climate.org/ publications/sparc-reports/sparc-report-no5/, 2010.

Steck, T. and von Clarmann, T.: Constrained profile retrieval applied to the observation mode of the Michelson Interferometer for Passive Atmospheric Sounding, Appl. Optics, 40, 35593571, 2001.

Stiller, G. P.: Interactive comment on "Observed temporal evolution of global mean age of stratospheric air for the 2002 to 2010 period" by G. P. Stiller et al., Atmos. Chem. Phys. Discuss., 11, C14654-C14654, 2012.
Stiller, G. P., von Clarmann, T., Höpfner, M., Glatthor, N., Grabowski, U., Kellmann, S., Kleinert, A., Linden, A., Milz, M., Reddmann, T., Steck, T., Fischer, H., Funke, B., LópezPuertas, M., and Engel, A.: Global distribution of mean age of stratospheric air from MIPAS SF 6 measurements, Atmos. Chem. Phys., 8, 677-695, doi:10.5194/acp-8-677-2008, 2008.

Strahan, S., Douglass, A., Nielsen, J., and Boering, K.: The $\mathrm{CO}_{2}$ seasonal cycle as tracer of transport, J. Geophys. Res., 103, 13729-13741, doi:10.1029/98JD01143, 1998.

Strunk, M., Engel, A., Schmidt, U., Volk, C. M., Wetter, T., Levin, I., and Glatzel-Mattheier, H.: $\mathrm{CO}_{2}$ and $\mathrm{SF}_{6}$ as stratospheric age tracers: consistency and the effect of mesospheric $\mathrm{SF}_{6}$-loss, Geophys. Res. Lett., 27, 341-344, doi:10.1029/1999GL011044, 2000.

Thompson, D. W. J. and Solomon, S.: Recent stratospheric climate trends as evidenced in radiosonde data: Global structure and tropospheric linkages, J. Climate, 18, 4785-4795, doi:10.1175/JCLI3585.1, 2005.

Tikhonov, A.: On the solution of incorrectly stated problems and method of regularization, Dokl. Akad. Nauk. SSSR+, 151, 501504, 1963.

Volk, C. M., Elkins, J. W., Fahey, D. W., Dutton, G. S., Gilligan, J. M., Loewenstein, M., Podolske, J. R., Chan, K. R., and Gunson, M. R.: Evaluation of source gas lifetimes from stratospheric observations, J. Geophys. Res., 102, 25543-25564, doi:10.1029/97JD02215, 1997.

von Clarmann, T., Grabowski, U., and Kiefer, M.: On the role of non-random errors in inverse problems in radiative transfer and other applications, J. Quant. Spectrosc. Ra., 71, 39-46, 2001.

von Clarmann, T., Stiller, G., Grabowski, U., Eckert, E., and Orphal, J.: Technical Note: Trend estimation from irregularly sampled, correlated data, Atmos. Chem. Phys., 10, 6737-6747, doi:10.5194/acp-10-6737-2010, 2010.

Waugh, D. W.: The age of stratospheric air, Nat. Geosci., 2, 14-16, 2009.

Waugh, D. W. and Hall, T. M.: Age of stratospheric air: theory, observations, and models, Rev. Geophys., 40, 1010, doi:10.1029/2000RG000101, 2002.

Waugh, D. W., Plumb, R. A., Elkins, J. W., Fahey, D. W., Boering, K. A., Dutton, G. S., Volk, C. M., Keim, E., Gao, R.-S., Daube, B. C., Wofsy, S. C., Loewenstein, M., Podolske, J. R., Chan, K. R., Proffitt, M. H., Kelly, K. K., Newman, P. A., and Lait, L. R.: Mixing of polar votex air into middle latitudes as revealed by tracer-tracer scatterplots, J. Geophys. Res., 102, 13119-13134, 1997. 